\title{
Specific tissue proteins 1 and 6 are involved in root biology during normal development and under symbiotic and pathogenic interactions in Medicago truncatula
}

\author{
Lucía Albornos $^{1,3} \cdot$ Virginia Casado-del-Castillo ${ }^{2,3} \cdot$ Ignacio Martín $^{1,3} \cdot$ José M. Díaz-Mínguez $^{2,3} \cdot$ Emilia Labrador $^{1,3}$. \\ Berta Dopico ${ }^{1,3}$ iD
}

Received: 5 June 2020 / Accepted: 11 December 2020 / Published online: 2 January 2021

(c) The Author(s), under exclusive licence to Springer-Verlag GmbH, DE part of Springer Nature 2021

\begin{abstract}
Main conclusion ST1 and ST6 are possibly involved in primary and lateral root and symbiotic nodule development, but only ST6 participates in the interaction with hemibiotrophic fungi.
\end{abstract}

\begin{abstract}
Specific tissue (ST) proteins have been shown to be involved in several processes related to plant nutritional status, development, and responses to biotic agents. In particular, ST1 and ST6 are mainly expressed in roots throughout plant development. Here, we analyze where and how the expression of the genes encoding both proteins are modulated in the legume model plant Medicago truncatula in response to the plant developmental program, nodulation induced by a beneficial nitrogen-fixing bacterium (Sinorhizobium meliloti) and the defense response triggered by a pathogenic hemibiotrophic fungus (Fusarium oxysporum). Gene expression results show that ST1 and ST6 participate in the vasculature development of both primary and lateral roots, although only ST6 is related to meristem activity. ST1 and ST6 clearly display different roles in the biotic interactions analyzed, where $S T 1$ is activated in response to a $\mathrm{N}_{2}$-fixing bacterium and ST6 is up-regulated after inoculation with $F$. oxysporum. The role of ST1 and ST6 in the nodulation process may be related to nodule organogenesis rather than to the establishment of the interaction itself, and an increase in ST6 correlates with the activation of the salicylic acid signaling pathway during the infection and colonization processes. These results further support the role of ST6 in response to hemibiotrophic fungi. This research contributes to the understanding of the complex network that controls root biology and strengthens the idea that ST proteins are involved in several processes such as primary and lateral root development, nodule organogenesis, and the plant-microbe interaction.
\end{abstract}

Keywords Fusarium oxysporum · Protein family PF10950 - Root development $\cdot$ ST protein $\cdot$ Sinorhizobium meliloti

\section{Abbreviations}

dpi Days post inoculation

ET Ethylene

ERF Ethylene response factor 1

Fo Fusarium oxysporum

Fom Fusarium oxysporum F. sp. medicaginis

Communicated by Dorothea Bartels.

Supplementary Information The online version contains supplementary material available at https://doi.org/10.1007/s0042 5-020-03538-4.

Berta Dopico

bdr@usal.es

Extended author information available on the last page of the article
GAL $\quad \beta$-Galactosidase

HEL Hevein-like protein

JA Jasmonic acid

LR Lateral root

PR Primary root

PR5 Pathogenesis related 5 protein

pST Promoter of Medicago truncatula ST gene

pST::GUS Transgenic Medicago truncatula plants carrying $p S T:: e G F P-G U S$ transgene

SA Salicylic acid

Sm Sinorhizobium meliloti

ST Specific tissue

VSP Vegetative storage protein 


\section{Introduction}

Plants are in constant interaction with other living organisms and have developed the ability to distinguish between innocuous or beneficial attackers. The recognition of an interacting partner can give rise to signaling cascades that trigger transcriptional changes specific to each organism. In many cases, responses to pathogens are designed to protect against attack; however, in the presence of beneficial interactors plants need to adapt accordingly. As a consequence, root development, for instance, is influenced by biotic interactions that force changes in gene expression and protein accumulation.

Specific Tissue (ST) proteins, belonging to the protein family PF10950, can be found in some dicotyledons plants and are encoded by multigenic families (Albornos et al. 2012). In the Medicago truncatula ST family (ST1 to ST6), ST1 (Medtr4g069810) is known to be related to plant nutritional status and $\mathrm{N}_{2}$-fixing symbiosis (Albornos et al. 2017), whereas ST6 (Medtr3g107810) is thought to participate in pathogenic or beneficial biotrophic interactions mediated by salicylic acid (SA) (Albornos et al. 2018). ST1 and, to a lesser extent, ST6 are mainly expressed in roots throughout plant development (Benedito et al. 2008). And, ST1 transcripts are induced by jasmonic acid (JA), which plays a major role in plant defense, and by auxins (IAA) and cytokinins (CK), hormones that positively regulate nodule organogenesis. At the same time, ST1 transcripts are repressed by negative regulators of nodule development such as abscisic acid (ABA), ethylene (ET), and SA (Oldroyd et al. 2011; Albornos et al. 2017; Carrère et al. 2020). Unlike ST1, ST6 has been associated with biotic interactions mediated by ET and SA signaling pathways. Thus, ST6 transcripts are induced by ET and SA but are not affected by JA (Albornos et al. 2018). There are only a few reports describing the combined action of ET and SA in defense, but some studies have determined that certain hemibiotrophic plant pathogens can trigger both pathways (Šašek et al. 2012). Many authors have noted that ST6 transcripts increase significantly in plants establishing interactions with arbuscular mycorrhiza (Liu et al. 2007), although the role played by hormones in this interaction is not well understood.

With regard to the gene regulation of ST1 and ST6 (Albornos et al. 2017, 2018), it could be that these two proteins are important to the changes observed in roots when interacting with symbiotic organisms like the $\mathrm{N}_{2}$-fixing bacterium Sinorhizobium meliloti $(\mathrm{Sm})$ or root pathogenic fungi such as Fusarium oxysporum (Fo).

$S m$ is an $\mathrm{N}_{2}$-fixing bacterium able to establish symbiosis with Medicago and with other legumes such as Melilotus and Trigonella. The root system is a key protagonist in establishing such interactions since nodules are specific organs of root origin that are necessary for fixing $\mathrm{N}_{2} . \mathrm{N}_{2}$-availability influences nodule development, as well as lateral root (LR) development and changes in root architecture (Mohd-Radzman et al. 2013). The release of flavonoids from the plant into the rhizosphere induces the bacterial nodulation factors recognized by receptor-like kinase complexes present in compatible host plants that trigger several changes related to symbiotic interaction, including the activation of symbiosis-associated genes in the host plant (Oldroyd 2013). During modulation, rhizobia invade the root hairs, move through the root epidermis via the infection threads, and are released from these infection threads to colonize the host cells of the root cortex through endocytosis, where they are enclosed by the symbiosome membrane. Suppression of host immunity appears to be required for the establishment of symbiosis, and defense-related genes experience a transient induction upon $S m$ inoculation, and then decrease to normal levels (Cao et al. 2017).

$F o$ is a soil-borne fungus that colonizes plant roots by penetrating wounds or through natural disruptions such as openings in the base of LR initials. The fungus colonizes the cortex and the central cylinder of roots and finally the vascular system of the host. This in turn clogs xylem vessels producing a decrease in the transport of water to the aerial parts of the plant and finally death. There are different formae speciales of $F o$ that infect specific host plants with distinctive colonization patterns and disease symptom development. A good pathosystem to study the effect of $F o$ in legumes is the one formed by $M$. truncatula and the hemibiotrophic fungus $F$. oxysporum f. sp. medicaginis (Fom) (Thatcher et al. 2016a). The invasion begins with the development of a hyphal network around root hairs and the upper part of the primary root (PR), followed by penetration and colonization of the root epidermis which causes a delay in root development (Ramírez-Suero et al. 2010). Once inside, disease symptoms start to develop depending on the degree of colonization. The fungus invades the cortex and central cylinder of the roots of resistant and susceptible cultivars in similar ways (Niño-Sánchez et al. 2015). Although M. truncatula resistant lines exhibit a delay in symptom development and a reduction of disease severity compared to susceptible cultivars, no differences in the degree of colonization of the root parenchyma and the central cylinder have been described (Ramírez-Suero et al. 2010). However, several studies have revealed that the $\mathrm{SA}, \mathrm{ET}$, and JA pathways influence the outcome of the disease produced by $F$. oxysporum in Arabidopsis (reviewed in Berrocal-Lobo and Molina 2008) and that the phytohormones involved in such interaction are dependent on the pathosystem (Di et al. 2016). For example, JA-mediated responses differ in $\mathrm{FO}_{\mathrm{O}}$-arabidopsis and $\mathrm{Fo}_{\mathrm{O}}$ barrel medic interactions, where JA-signaling is optimal for 
carrying out differing roles depending on the host (Thatcher et al. 2016a).

As mentioned above, $S T 1$ and $S T 6$ transcripts are mainly expressed in roots and are known to be related to biotic interactions, and exhibit opposing accumulation profiles when exposed to SA, ET, and JA, hormones associated with the activation of different defense pathways (Albornos et al. 2017,2018 ). Hence, the aim of this work was to analyze the role of ST proteins in roots under both normal growth conditions and when challenged by two root-interacting microorganisms: the beneficial $\mathrm{N}_{2}$-fixing bacterium $\mathrm{Sm}$ and the harmful root pathogenic hemibiotrophic fungus Fom.

\section{Materials and methods}

\section{Plant material and growth conditions}

Medicago truncatula cv Jemalong lines A17 and 2HA (derived from A17) were used. Transgenic plants carrying the $p S T:: e G F P-G U S$ transgene ( $p S T:: G U S$ hereinafter) were previously constructed using the line 2HA (Albornos et al. 2019) following the procedure described in Chabaud et al. (2003).

Seeds were chemically scarified with $\mathrm{H}_{2} \mathrm{SO}_{4} 95 \%$ (v/v) for 6 min, surface sterilized with commercial bleach (5\% chlorine solution) for $4 \mathrm{~min}$, placed in Petri dishes with solid modified Fahräeus medium (Barker et al. 2006) supplemented with $\mathrm{NH}_{4} \mathrm{NO}_{3}$ to a final $1 \mathrm{mM}$ concentration of $\mathrm{N}$ (Fahräeus-N) and stratified for 2 days at $4{ }^{\circ} \mathrm{C}$ in the dark before germination. Seeds were germinated in the dark at $25^{\circ} \mathrm{C}$ for $16 \mathrm{~h}$. For growing plants in pots, germinated seeds were transferred to a mixture of soil/vermiculite $(3 / 1, \mathrm{v} / \mathrm{v})$ and kept in a growth chamber (Aralab, Portugal) at $25^{\circ} \mathrm{C}$ and with $60 \%$ humidity and a 16/8 h light/dark photoperiod (light provided by a mix of cool-white and red fluorescent tubes at a light intensity of approximately $200-300 \mu \mathrm{mol} \mathrm{m}^{-2} \mathrm{~s}^{-1}$ ).

To study plant-microorganism interactions, A17 and 2HA germinated seeds were transferred to square Petri dishes with Fahräeus-N medium. A layer of sterile filter paper was laid over the agar to keep the roots growing on the surface. The plates were placed vertically in the growth chamber mentioned above with the roots covered from light. The procedures used for infection with the microorganisms are detailed later in this section.

\section{Bacterial strain, culture conditions and nodulation of Medicago truncatula}

The strain used for the nodulation assays was Sinorhizobium meliloti (Sm) RCR2011 pXLGD4 (Ardourel et al. 1994) which is resistant to tetracycline and constitutively expresses the lac $\mathrm{Z}$ gene. The bacteria were grown in liquid TY/Ca medium ( $5 \mathrm{~g} \mathrm{l}^{-1}$ Bacto-tryptone, $3 \mathrm{~g} \mathrm{l}^{-1}$ yeast extract, $6 \mathrm{mM}$ $\mathrm{CaCl}_{2}, \mathrm{pH}$ 7.2) supplemented with $10 \mu \mathrm{g} \mathrm{ml}^{-1}$ of tetracycline for $24 \mathrm{~h}$ at $28^{\circ} \mathrm{C}$ and $180 \mathrm{rpm}$. The culture was then diluted to a final $\mathrm{OD}_{600}$ of 0.01 for inoculating the plants.

Medicago truncatula wild-type (WT) plants A17 and 2HA and transgenic plants carrying pST1::GUS or pST6::GUS transgenes were inoculated with $S m$. At least three different transgenic lines were used. M. truncatula seeds were grown in solid Fahräeus medium with no nitrogen supplement. Seven-day-old plantlets were inoculated using $1-2 \mathrm{ml}$ of the previously described culture per root and incubated in a horizontal position for $1 \mathrm{~h}$. Afterwards, all excess liquid was removed and the plates were returned to a vertical position. The control plants were kept in Fahräeus$\mathrm{N}$ and incubated with water.

The WT and transgenic 2HA-inoculated plantlets were collected at 4,8 , and 15 days post-inoculation (dpi) for carrying out $\beta$-glucuronidase (GUS) and magenta- $\beta$ galactosidase (GAL) activity assays (see below). The WT line A17 was used for RNA extraction. All plant material was immediately frozen at $-80{ }^{\circ} \mathrm{C}$. At $4 \mathrm{dpi}$, the most apical half of the root was collected from the control and the inoculated plants (no nodules were visible). At 8 and $15 \mathrm{dpi}$, the nodules and root segments adjacent to the nodules (nonodule root areas) were collected separately as equally sized segments from the non-inoculated roots. Three independent inoculation experiments were performed.

\section{Fungal strain, culture conditions and infection of Medicago truncatula}

The F. oxysporum f. sp. medicaginis (Fom) strain 179.29 was used in this study and was grown as previously described (Alves-Santos et al. 1999; de Vega-Bartol et al. 2011). Fungal cultures were established from frozen mycelia stored in $25 \%$ glycerol (v/v) at $-80{ }^{\circ} \mathrm{C}$ and incubated in liquid sporulation medium (6\% sucrose, $0.7 \% \mathrm{NaNO}_{3}, 0.3 \%$ tryptone, $\left.0.1 \% \mathrm{KH}_{2} \mathrm{PO}_{4}, 0.05 \% \mathrm{MgSO}_{4} \times 7 \mathrm{H}_{2} \mathrm{O}, 0.05 \% \mathrm{KCl}(\mathrm{pH} 7)\right)$ at $25{ }^{\circ} \mathrm{C}$ with continuous light for 5 days at $180 \mathrm{rpm}$. A suspension of $10^{6}$ spores $\mathrm{ml}^{-1}$ was obtained. Plants of $M$. truncatula A17 were grown vertically on solid Farhäeus medium as described above and 4 days-old plantlets were inoculated as follows. The plates were placed horizontally, and the roots were carefully soaked in the spore suspension (3-3.5 $\mathrm{ml}$ per plate). After incubating for $30 \mathrm{~min}$, the excess liquid was removed, and plates were returned to a vertical position. The infected plants were kept in the growth chamber at $25{ }^{\circ} \mathrm{C}$ and $75 \%$ relative humidity with a $16 / 8 \mathrm{~h}$ light/ dark photoperiod until collected. Plant infection assays were repeated three times in a randomized design and a total of 60 plants were analyzed. Roots were excised and collected at 1 , $2,3,7,10$, and $15 \mathrm{dpi}$ and immediately frozen at $-80^{\circ} \mathrm{C}$ for RNA extraction for RT-qPCR analysis. 
Furthermore, WT plants of $M$. truncatula $2 \mathrm{HA}$ and at least three transgenic lines carrying pST1::GUS or pST6::GUS transgenes were also inoculated as described in this section. Plantlets were collected at 1, 2, 3, 7, 10, and 15 dpi and immediately analyzed for GUS activity (see below).

\section{RNA extraction and cDNA synthesis}

One hundred $\mathrm{mg}$ of root or nodule samples, obtained as indicated above, were used to obtain RNA using the Nucleospin ${ }^{\circledR}$ RNA plant kit (Macherey-Nagel) and an extra DNase treatment was performed using the TURBO DNAfree $^{\mathrm{TM}}$ kit (Ambion, Invitrogen) according to the manufacturer's recommendations. To avoid RNA degradation, all instruments were carefully washed with the RNase inhibitor RNaseZap ${ }^{\circledR}$ solution (Ambion, Austin, TX, USA). RNA quantification was performed using a nanophotometer and checked for integrity by agarose gel electrophoresis.

First-strand complementary DNA (cDNA) was synthesized from $1 \mu \mathrm{g}$ of RNA in a reaction volume of $20 \mu \mathrm{l}$ by priming with oligo dT (final concentration $2.5 \mu \mathrm{M}$ ) using PrimerScript ${ }^{\mathrm{TM}} \mathrm{RT}$ reagent kit (Takara Bio Inc.) following the manufacturer's instructions.

\section{Quantitative reverse-transcription polymerase chain reaction (RT-qPCR)}

The cDNA obtained as indicated above was used undiluted for RT-qPCR experiments. The efficiency of each pair of primers was verified as previously described (Niño-Sánchez et al. 2015). Amplifications were performed in a StepOnePlus $^{\mathrm{TM}}$ Real-Time PCR system (Applied Biosystems, Foster City, CA, USA) according to the manufacturer's recommendations.

Specific primers for $S T 1$ and $S T 6$ genes were designed flanking the intron sequence (Albornos et al. 2017, 2018). The EFl $\alpha$ gene of M. truncatula was used as the endogenous reference gene. MtVSP (Ramírez-Suero et al. 2010), MtERF1, MtHEL, and MtPR5 (Gao et al. 2007) were amplified to determine the signaling pathways involved in Fom infection and Sm nodulation. MtNCR (Horváth et al. 2015) and MtNIN (Chen et al. 2017) were used to check nodulation progress. All primers used in the RT-qPCR experiments are listed in Supplementary Table S1.

Relative expression levels of each gene were calculated by the $2^{-\Delta \Delta C t}$ method (Livak and Schmittgen 2001), which allows for relative quantification of the target gene compared to the housekeeping gene $(E F 1 \alpha)$. The $\mathrm{Ct}$ values obtained were used to calculate the Relative Quantify of transcript (RQ) according to the formula $R Q=2^{\wedge}(-\Delta \Delta \mathrm{Ct})$, where $\Delta \Delta \mathrm{Ct}=\Delta \mathrm{Ct}^{\text {specific sample }}-\Delta \mathrm{Ct}^{\text {reference sample }}$, being $\Delta \mathrm{Ct}=\mathrm{Ct}^{\text {target gene }}-\mathrm{Ct}^{\text {housekeeping gene }}$ for any given sample. In order not to underestimate or overestimate the level of
mRNA, the reference sample $(R Q=1.0)$ for each sample set was always that one whose accumulation of mRNA was the lowest among all the samples with a $\mathrm{Ct}$ value inside the range of primers efficiency. Three sets of samples from different infection assays were used (biological replicates), two independent cDNA preparations per biological replicate were obtained, and three replicas of each cDNA were analyzed to calculate the mean and standard deviation. Statistical tests to find significant variations were performed with SPSS (IBM SPSS Statistics 23): the Student's $t$ test, when comparing two conditions, and the ANOVA test followed by Scheffe test when comparing three different conditions. Significant differences were considered for $P$ values less than 0.05 , which were: $*, 95 \%$ confidence level $(P$ value $<0.05)$; **, 99\% confidence level $(P$ value $<0.01)$; and $* * *, 99.9 \%$ confidence level $(P$ value $<0.001)$.

\section{GUS and GAL staining and histological analysis}

We analyzed the GUS enzymatic activity in $M$. truncatula cv Jemalong line 2HA WT and transgenic plants with the $p S T:: G U S$ construct. The enzymatic reaction was performed overnight at $37^{\circ} \mathrm{C}$ using the substrate 5-bromo-4-chloro-3indolyl- $\beta$-D-glucuronic acid (X-GlucA) (Duchefa, Haarlem, The Netherlands) as described by Albornos et al. (2019). All analyses were performed in WT plants, and in at least three plants of each of the three independent transgenic lines. Only coincident patterns of expression were considered as positive.

GUS activity was assayed in roots of 3-, 6- and 10-day-old plantlets (both light- and dark-grown) and in plants inoculated with $\mathrm{Sm}$ and Fom. Furthermore, plants inoculated with Sm were assayed for GAL activity (magenta-GAL) using the colorimetric substrate 5-bromo-6-chloro-3-indolyl- $\beta$ D-galactopyranoside (X-Gal) (Sigma, ST. Louis, MO, USA) to localize the rhizobia (Pichon et al. 1994). Images were acquired as indicated in Albornos et al. (2019).

After performing the GUS or the GUS/magenta-GAL histochemical reactions, the radicles from 6-day-old plants and nodules at 4,8 , and 15 dpi were fixed, embedded in paraffin, and sectioned for microscopy analysis as indicated in Albornos et al. (2019).

\section{Results}

\section{pST1 and pST6 are differentially activated in the root apex and during lateral root development}

The activity of ST1 and ST6 promoters ( $p S T 1$ and $p S T 6$, respectively) was analyzed in the roots of green (Figs. 1, 2, respectively) and etiolated (Supplementary Fig. S1) $M$. truncatula seedlings carrying the $p S T 1:: G U S$ or $p S T 6:: G U S$ 
a

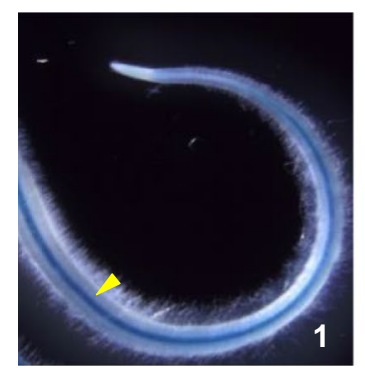

6 -d-old

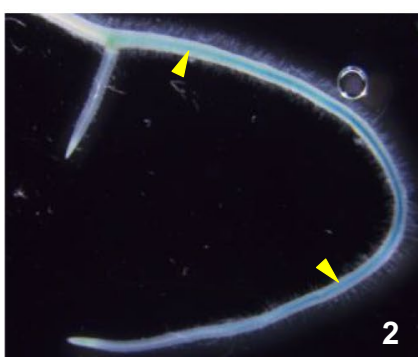

10-d-old
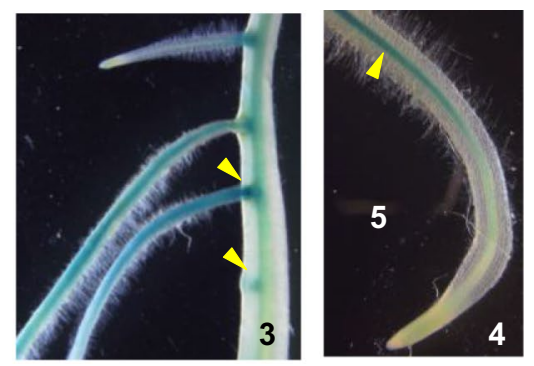
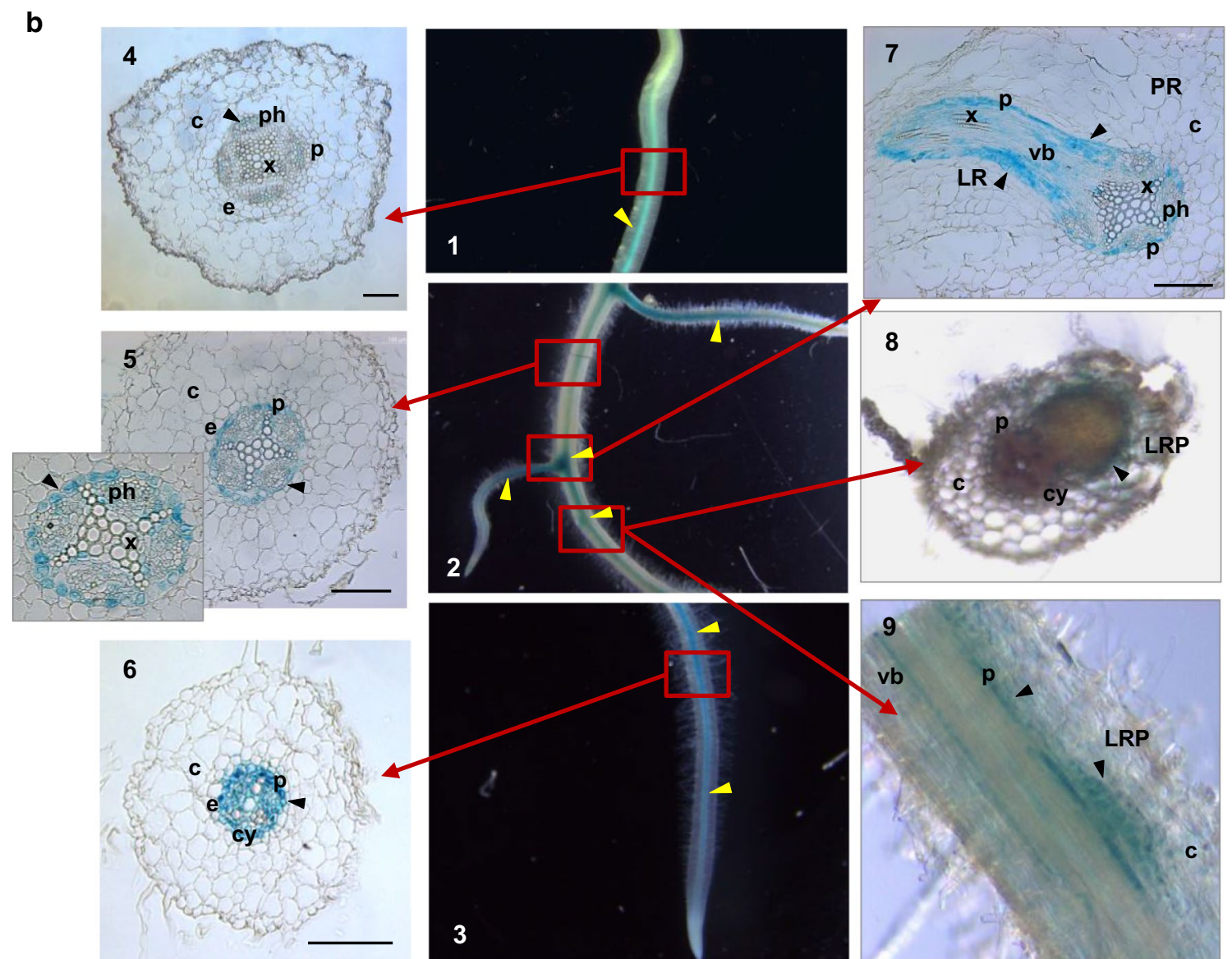

Fig. 1 GUS activity in roots of green transgenic Medicago truncatula pST1::GUS plantlets throughout the development. a Roots of 3 (1), 6- (2) and 10-d-old $(3,4)$ plantlets. b Detail of 10-d-old root basal (1), central (2) and apical (3); transversal sections of basal (4), central (5) and apical (6) primary root (PR) and PR with lateral root (LR) junction (7); handmade transversal (8) and longitudinal (9) sections of lateral root primordium (LRP). $c$ cortex, $c y$ vascular cylinder, $e$ endodermis, $p$ pericycle, $p h$ phloem, $v b$ vascular bundle, $s c$ scleren-

transgenes. WT control plants were also analyzed for endogenous GUS activity, although no activity was detected (data not shown). All results obtained are summarized in Table 1.

pST1 was active in the central cylinder of the primary and lateral roots regardless of the age of the plant (Fig. 1a, chyma, $v b$ vascular bundle, $v c$ vascular cambium, $x$ xylem. At least three plants of three independent transgenic lines were analyzed. Only when several independent transgenic lines displayed the same pattern of expression of the reporter gene was it consider as positive. Bars $100 \mu \mathrm{m}$. The blue color indicates the zones with GUS activity driven by $p S T 1$. The yellow (whole organ) and black (histological sections) arrowheads show the key features

b7), and along the PR, the blue staining was darker around the areas of the emergence of the LR (Fig. 1a3, b2). The activity of pST1 increased toward the apical region of the PR in 6-day-old green plantlets (Fig. 1b1-b3) and histological sections confirmed that activity was restricted to the vascular 


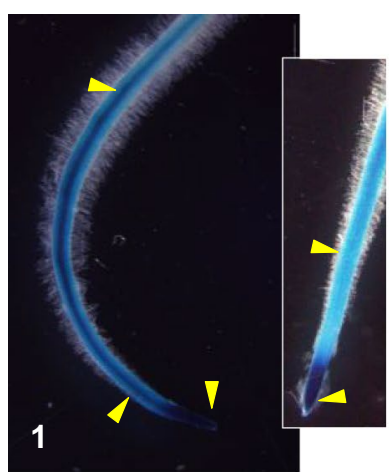

6-d-old

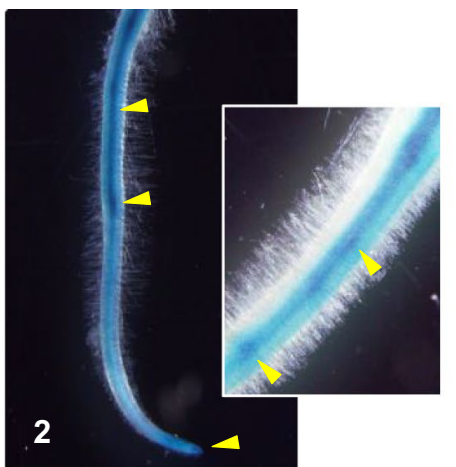

10-d-old

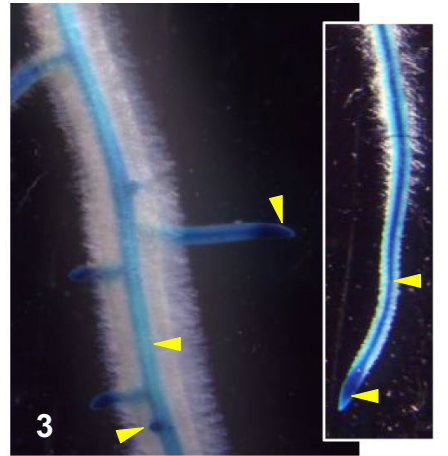

b
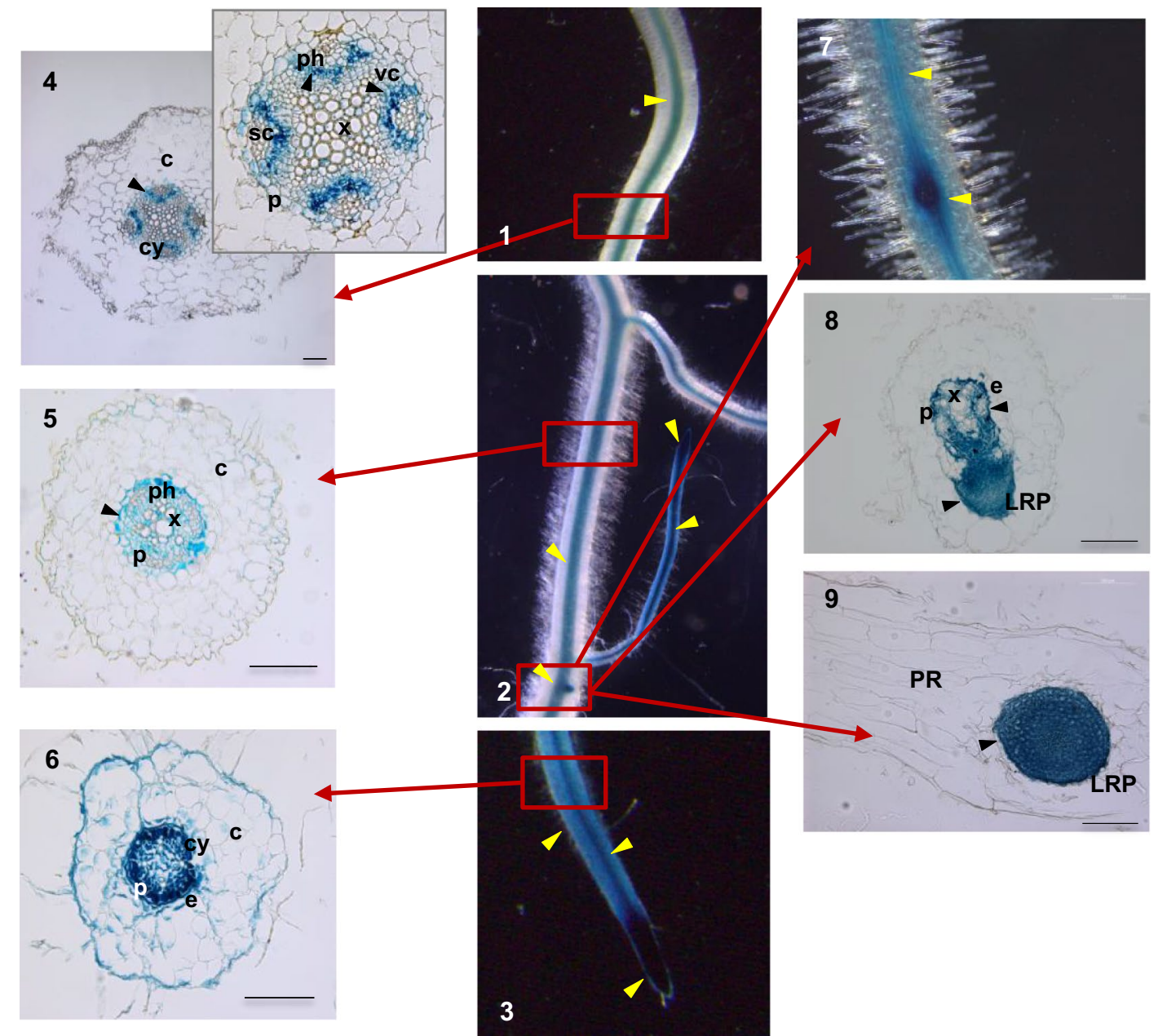

Fig. 2 GUS activity in roots of green transgenic Medicago truncatula pST6::GUS plantlets throughout the development. a Roots of 3 (1), 6- (2) and 10-d-old $(3,4)$ plantlets. b Detail of 10-d-old root basal (1), central (2) and apical (3); transversal sections of basal (4), central (5) and apical (6) primary root (PR); GUS activity in an emerging lateral root (LR) (7); transversal (8) and longitudinal (9) sections of a PR with lateral root primordia (LRP). $c$ cortex, $c y$ vascular cylinder, $e$ endodermis, $p$ pericycle, $p h$ phloem, $s c$ sclerenchyma, $v b$ vascular

bundle, $v c$ vascular cambium, $x$ xylem. At least three plants of three independent transgenic lines were analyzed. Only when several independent transgenic lines displayed the same pattern of expression of the reporter gene was it consider as positive. Bars $100 \mu \mathrm{m}$. The blue color indicates the zones with GUS activity driven by $p S T 6$. The yellow (whole organ) and black (histological sections) arrowheads show the key features 
Table 1 Summary of $p S T 1$ and pST6 activation pattern in root areas and tissues

\begin{tabular}{lllll}
\hline Organ/tissue & pST1 activity (figures) & pST6 activity (figures) \\
\hline Primary root & & & & \\
$\quad$ Apical root area & & (Fig. 1b4) & ++++ & (Fig. 2b3) \\
Meristematic area & - & (Fig. 1b4) & ++ & (Fig. 2b3) \\
Elongation area & - & (Fig. 1b6) & ++ & (Fig. 2b6) \\
Cortex & - & (Fig. 1a2) & ++++ & (Fig. 2a3) \\
Central cylinder (CC) & ++++ & (Fig. 1b4) & ++++ & (Fig. 2b4) \\
Basal phloem & + & (Fig. 1b4) & ++++ & (Fig. 2b4) \\
Basal vascular cambium & - & (Fig. 1b5, b6) & ++++ & (Fig. 2b5, b6) \\
Medium and apical (CC) & +++ & & & \\
Lateral root (LR) & & (Fig. 1b8) & ++++ & (Fig. 2b8) \\
LR primordia & & (Fig. 1b8) & ++++ & (Fig. 2b9) \\
Cell outer layer & ++ & (Fig. 1a3) & ++++ & (Fig. 2a3) \\
Central cells & - & (Fig. 1b2) & ++++ & (Fig. 2b2) \\
LR emergence & ++++ & (Fig. 1a3) & ++++ & (Fig. 2b2) \\
Apical root area & - & & \\
Central cylinder & ++++ & &
\end{tabular}

A dash (-) indicates no promoter activity and the number of plus symbols $(+)$ correlate with promoter activation intensity. Quantification is approximated and there is no equivalence between both promoters. Only the most illustrative figure(s) are indicated in the table although some results could also be observed in other figures cylinder. Moreover, activity in the basal zone was limited to the primary phloem (Fig. 1b4), while in the central and apical zones activity was generalized in the stele (Fig. 1b5, b6). Histological sections also showed that pST1 was active in LR primordia (LRP) (Fig. 1a3, b2, b8, b9), and in the stele of the developing LR (Fig. 1b7).

Strong pST6 activity in the root (Fig. 2) was also observed in the meristematic area (Fig. 2a, b3). However, unlike pST1, pST6 activity decreased throughout root development (Fig. 2a1-a3) and along the root axis, being more intense in the root tips (Fig. 2a1, a3, b1, b2, b3), which was confirmed in the histological sections (Fig. 2b4-b6). The staining was restricted to the vascular cylinder (Fig. 2a2, a3, b1, b2) except in the younger roots (Fig. 2a1) and in the most apical region (including meristematic and growth areas) (Fig. 2a2, a3, b3). In the histological sections of the basal part of the root the staining was intense in the vascular cambium and the phloem (Fig. 2b4), whereas in the central part, the blue dye was uniform in the whole vascular cylinder and the pericycle (Fig. 2b5). The apical section showed generalized dark staining in the stele (Fig. 2b6), which correlates with the observations made at the macroscopic level (Fig. 2b3). The activity pattern was similar in PR and LR (Fig. 2a3, b2). The staining of the LR started from the LRP formation; in fact, a strong level of staining was observed in the PR where a LR would emerge (Fig. 2a2, a3, b2, b7). Emerging LR displayed an intense blue in all cells (Fig. 2a3, b2, b8, b9). Finally, the activity of pST6 in LR resembled that found in the PR in 3-day-old seedlings (Fig. 2a1) with the blue dye progressively restricted to the vascular cylinder (Fig. 2b2) along LR growth, supporting the idea that the activity of this promoter decreases throughout maturation.

The activity of $p S T 1$ and pST6 in the roots of etiolated seedlings (Supplementary Fig. S1a, b, respectively) was similar to that detected in the green plantlets, except that pST6 staining was less intense. In the histological sections of the roots of 6-day-old plantlets grown in the dark, we observed that pST1 and pST6 activity was confined to the vascular cylinder (Supplementary Fig. S1a4, b4).

\section{ST1 and ST6 exhibit different accumulation patterns during nodulation}

LR and nodules share developmental programs (Franssen et al. 2015). Therefore, we decided to analyze whether ST1 and ST6 have a role in nodulation by studying both ST1 and ST6 transcript levels during the establishment of $\mathrm{N}_{2}$-fixing symbiosis (Fig. 3). Nodulated roots were analyzed at three time points during infection with $\mathrm{Sm}$ and nodule organogenesis: at $4 \mathrm{dpi}$, when several nodule primordia per root were observed; at 8 dpi when nearly-spherical non-fixing nodules appeared; and finally at $15 \mathrm{dpi}$ when nodules showed a pink coloration, indicative of $\mathrm{N}_{2}$ fixation.

After inoculation, the transcripts of ST1 in no-nodule root areas increased, while ST6 decreased (Fig. 3a, b) compared to uninfected roots. Regardless of the transcript levels of ST1 and ST6 during the nodulation process, ST1 was always statistically higher than ST6 (data not shown). 

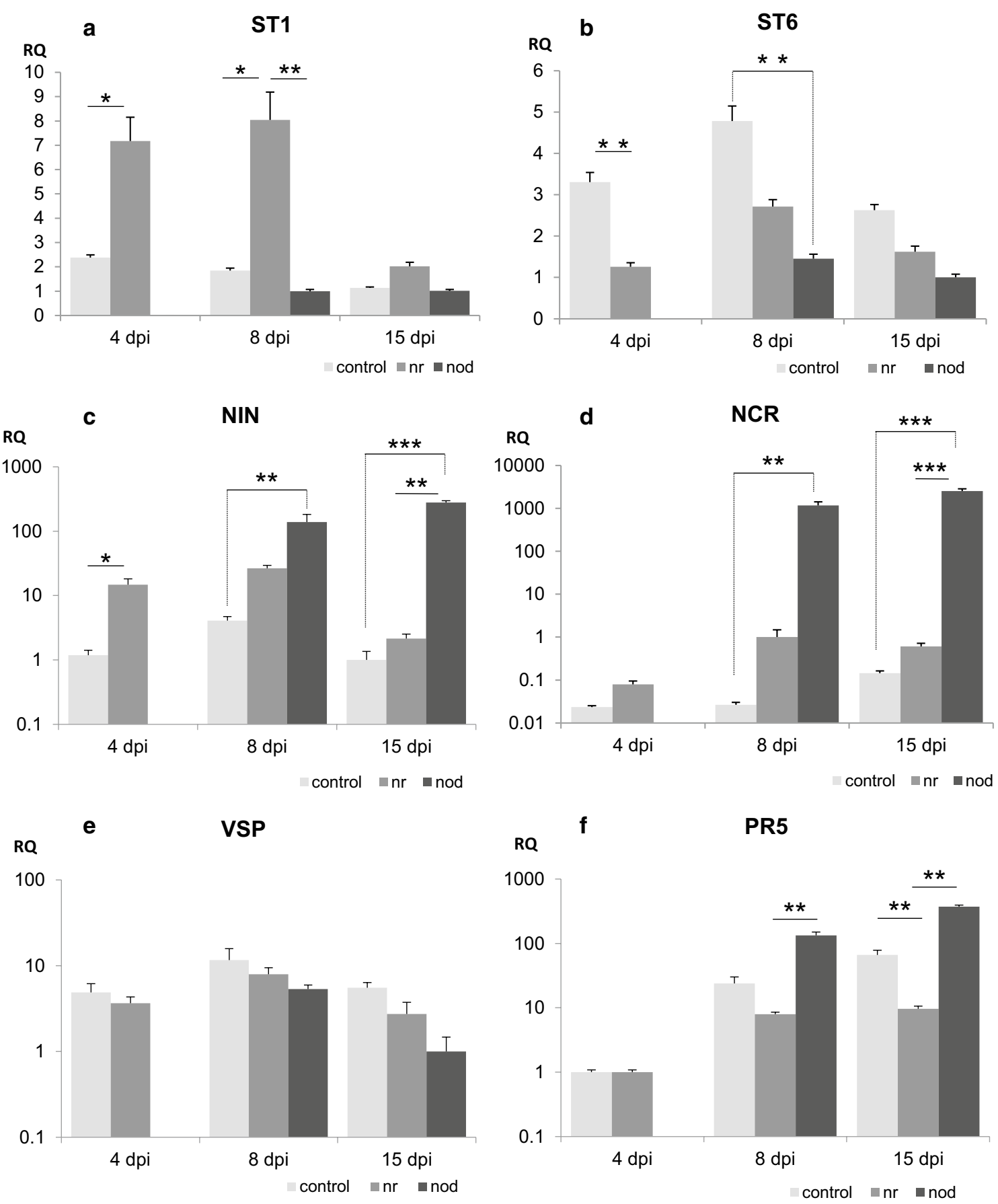

Fig. 3 RT-qPCR of Medicago truncatula ST1 and ST6 transcripts, nodule inception $(N I N)$ and nodule-specific cysteine-rich peptide $(N C R)$ as marker genes for nodulation and VSP and PR5 for JA and SA as defense pathways markers respectively, after inoculation with Sinorhizobium meliloti. Four-d-old M. truncatula WT plants were inoculated with $\mathrm{Sm}$ and nodules (nod) and fragments of inoculated roots without nodules (nr) were collected to analyze transcript accumulation by RT-qPCR at 4-, 8- and 15-days post infection (dpi) and compared with noninoculated (control) roots. a ST1. b ST6. c NIN, nodule inception protein. d NCR, nodule-specific cysteine-rich peptide. e VSP, vegetative storage protein. f PR5, pathogenesis-related 5. The expression ratios were normalized by using the Medicago

truncatula EF1 $\alpha$ gene as an endogenous control. Scale units express normalized relative quantities (RQ) and NIN, NCR, VSP, and PR5 are represented in a logarithmic scale to visualize the less represented transcripts. An arbitrary value of 1.0 was denoted for the transcript level of the reference samples being nod 8 dpi for ST1, nod 15 dpi for ST6 and VSP, control 15 dpi for NIN, nr 8 dpi for NCR, and control 4 dpi for PR5. Three independent nodulation experiments were used for RNA extraction. Statistical analyzes were conducted performing Student's test ( 4 dpi) and ANOVA test followed by Scheffe test ( 8 and $15 \mathrm{dpi}$ ) as stated in the Materials and methods section considering 3 levels of significance: $* P<0.05$; $* * P<0.01$; $* * * P<0.001$ 
Additionally, the presence of both $S T$ transcripts in nodules supports a putative function in this organ (Fig. 3a, b).

To determine that nodulation progressed adequately, two markers of the nodulation process were used: nodule inception $(N I N)$, related to the onset of symbiosis, and nodule-specific cysteine-rich peptide $(N C R)$ associated with the later stages of the process (Fig. 3c, d). The levels of the transcript are represented on an exponential scale to facilitate their visualization. NIN and NCR transcript accumulation showed a similar pattern, although $N C R$ accumulation was delayed, with both transcripts being more abundant in nodulated than in uninfected roots, mainly in the nodules themselves. NIN but not NCR transcripts increased in no-nodule root areas at 4 dpi more than tenfold with respect to the control roots. However, NIN increased in the nodule more than 30 -fold (Fig. 3c) and NCR more than 40,000- and 15,000-fold greater at 8 and 15 dpi, respectively (Fig. 3d).

Finally, and since the plant hormones JA and SA modified the level of STI and ST6 transcripts (Albornos et al. 2017, 2018), we studied the changes in vegetative storage protein (VSP) and pathogenesis related $5(P R 5)$ marker genes, which are indicative of the activation of the JA- and SA-signaling pathways respectively. The VSP transcripts were not significantly altered during the nodulation process (Fig. 3e), while an increase in the $P R 5$ transcript was found in the nodules from $8 \mathrm{dpi}$ (Fig. 3f) and a decrease in the no-nodule root areas, which was more significant at $15 \mathrm{dpi}$ as compared to the control roots.

\section{pST1 and pST6 are mainly active in the vascular bundle and in the meristem of the nodules, respectively}

Since ST1 and ST6 transcripts are present in nodules (Fig. 3a, b), we decided to check whether the activity of pST1 and pST6 was specific to some tissues within the nodule using transgenic plants pST1::GUS (Fig. 4) and pST6::GUS (Fig. 5) inoculated with $\mathrm{Sm}$. To facilitate these analyses a magenta-GAL staining (purple) was carried out to localize the rhizobia. All results obtained are summarized in Table 2. $p S T 1$ and $p S T 6$ are active from the first cortical divisions all throughout nodule development, albeit with some differences. At $4 \mathrm{dpi}$, blue staining was observed in the nodule primordium of pST1::GUS (Fig. 4.1-4) and pST6::GUS (Fig. 5.1-5) transgenics, apparent as a darker area in the root vascular cylinder and a blue coloration in the proximal root cortex, with no obvious staining in the non-infected roots (Figs. 1b5, 2b5). When these nodule initials were observed in detail in longitudinal (Fig. 4.2) and transverse (Fig. 4.3) sections of hand-cut or paraffinembedded tissue (Fig. 4.4), pST1 was active (blue) around the bacteria (purple) (Fig. 4.2-4) in the cortical cells that accommodate the rhizobia. A similar pattern was observed for $p S T 6$ (Fig. 5.2-5), whose activation in the cortical cells was a consequence of the infection (Fig. 5.2). Once the bacteria had entered the root (Fig. 5.3), GUS activity could be detected in the inner cortex at the site of infection, spread later to more cortical cell layers, and became stronger in the
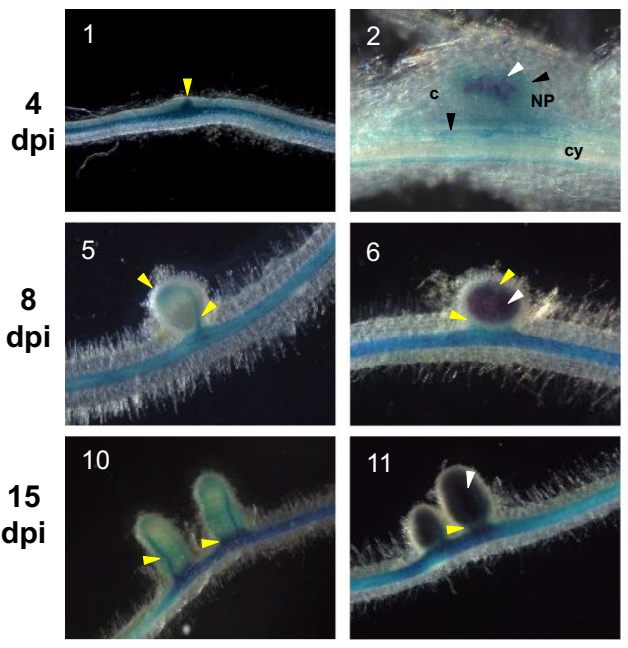
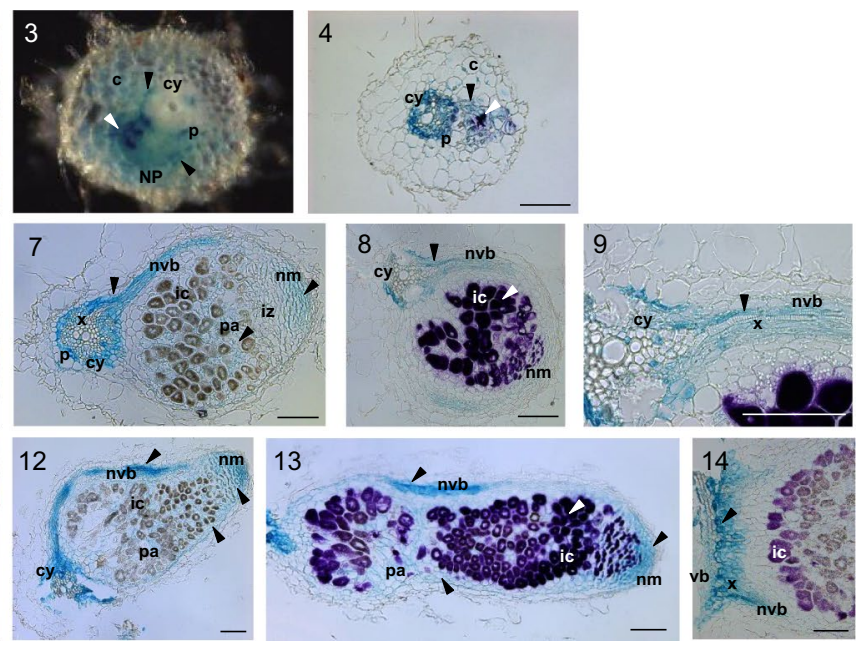

Fig. 4 GUS activity of pST1::GUS transgenic Medicago truncatula inoculated with Sinorhizobium meliloti. Four-d-old M. truncatula pST1::GUS transgenic plants were inoculated with $\mathrm{Sm}$ and GUS activity and GAL activity were determined at 4 - (1 to 4), 8- (5 to 9) and 15 - (10 to 14 ) days post-infection (dpi) in the whole root $(1,2,5$, $6,10,11$ ); hand-made transversal section (3) and histological sections of paraffin-fixed roots $(4,7-9,12-14)$. Blue staining indicates $p S T 1$ activation (the yellow (whole organ) and black (histological sections)

arrowheads show the key features) and magenta-GAL staining marks the presence of rhizobia (purple, white arrowhead). $c$ cortex, $c y$ vascular cylinder, ic infected cell, iz nodule infection zone, $L R P$ lateral root primordium, $n m$ nodule meristem, $N P$ nodule primordium, $n v b$ nodule vascular bundle, $p$ pericycle, $p a$ parenchyma, $v b$ vascular bundle, $x$ xylem. At least three plants of three independent transgenic lines were analyzed. Bars $100 \mu \mathrm{m}$ 

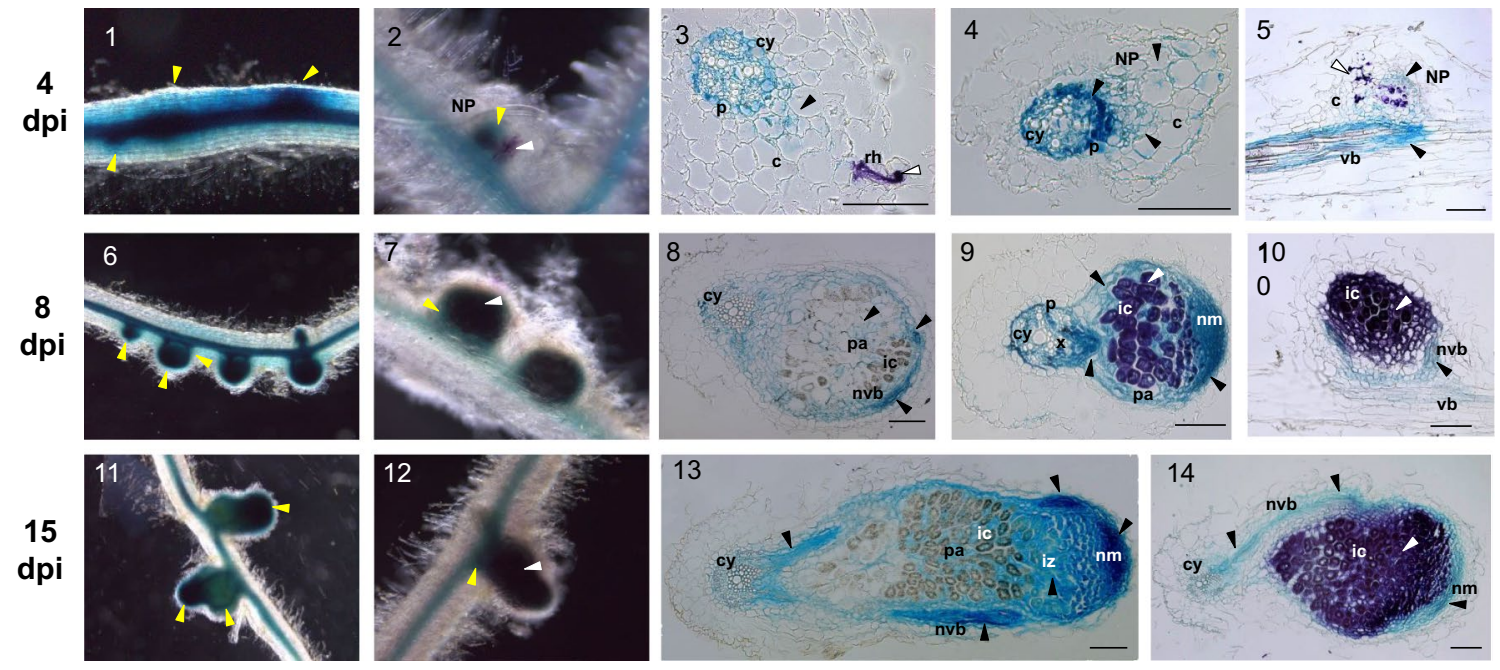

Fig. 5 GUS activity of pST6::GUS transgenic Medicago truncatula inoculated with Sinorhizobium meliloti. Four-d-old M. truncatula pST6::GUS transgenic plants were inoculated with $\mathrm{Sm}$ and GUS activity and GAL activity were determined at 4 - (1 to 4 ), 8 - (5 to 9 ) and 15- (10 to 14) days post-infection (dpi) in the whole root $(1,2,5$, $6,10,11$ ); hand-made transversal Sect. (3) and histological sections of paraffin-fixed roots $(4,7-9,12-14)$. Blue staining indicates pST6 activation (the yellow (whole organ) and black (histological sections) arrowheads show the key features) and magenta-GAL staining marks the presence of rhizobia (purple, white arrowhead). $c$ cortex, $c y$ vascular cylinder, ic infected cell, $i z$ nodule infection zone, $L R P$ lateral root primordium, $n m$ nodule meristem, $N P$ nodule primordium, $n v b$ nodule vascular bundle, $p$ pericycle, $p a$ parenchyma, $r h$ root hair, $v b$ vascular bundle, $x$ xylem. At least three plants of three independent transgenic lines were analyzed. Bars $100 \mu \mathrm{m}$
Table 2 Summary of $p S T 1$ and $p S T 6$ activation pattern in nodules

\begin{tabular}{lllll}
\hline Nodulation stages/tissues & pST1 activity (figures) & pST6 activity (figures) \\
\hline 4 dpi & & & & \\
$\quad$ Nodule primordia & +++ & (Fig. 4.2, 3) & ++++ & (Fig. 5.2 5) \\
$\quad$ Cortical cells & ++ & (Fig. 4.3) & ++ & (Fig. 5.3) \\
$\quad$ Inner cortex & + & (Fig. 4.4) & + & (Fig. 5.3) \\
$\quad \begin{array}{l}\text { Pericycle } \\
8 \text { dpi }\end{array}$ & ++ & (Fig. 4.4) & +++ & (Fig. 5.4) \\
Nodule vascular bundle & ++++ & (Fig. 4.5, 7) & +++ & (Fig. 5.6, 8) \\
Nodule meristem & + & (Fig. 4.5, 7) & ++++ & (Fig. 5.6, 9) \\
Infection zone & - & (Fig. 4.7) & +++ & (Fig. 5.9) \\
Uninfected parenchyma & + & (Fig. 4.7) & +++ & (Fig. 5.8) \\
Vasculature connection & ++++ & (Fig. 4.7) & ++ & (Fig. 5.10) \\
15 dpi & & & & (Fig. 5.11, 14) \\
Nodule vascular bundle & ++++ & (Fig. 4.10, 12) & +++ & (Fig. 5.11, 13) \\
Nodule meristem & ++ & (Fig. 4.10, 12) & ++++ & (Fig. 5.13) \\
Infection zone & - & (Fig. 4.12) & ++++ & (Fig. 5.13) \\
Uninfected parenchyma & + & (Fig. 4.13) & +++ & (Fig. 5.13, 14) \\
Vasculature connection & +++ & (Fig. 4.12, 14) & +++ & \\
\hline
\end{tabular}

A dash (-) indicates no promoter activity and the number of plus symbols $(+)$ correlate with promoter activation intensity. Quantification is approximated and there is no equivalence between both promoters. Only the most illustrative figure(s) are indicated in the table although some results could also be observed in other figures. Dpi, days post-infection pericycle (Fig. 5.4), which was the same in the longitudinal sections (Fig. 5.5).

The activity of both promoters was different in the whole nodule at 8 and 15 dpi. $p S T 1$ activity was localized in the vascular bundle and the meristem of the nodule (Fig. 4.5, 10) whereas $p S T 6$ showed a generalized activity throughout the entire organ (Fig. 5.6, 11), with the rhizobia filling the nodules in both cases (Figs. 4.6, 11, 5.7, 12). The histological 
sections of these nodules confirmed these differences. pST1 was mainly active around the vascular bundle (Fig. 4.7-9, 12-14), uninterruptedly from the central cylinder of the root hosting the nodule to the vasculature in the new developing organ (Fig. 4.7, 12), and to a lesser extent in the meristematic cells and in the parenchyma surrounding the infected cells (Fig. 4.7, 12) that accommodate the bacteroids (Fig. 4.8, 13). A closer view at the nodule base in a longitudinal section (Fig. 4.14) showed that the darker staining observed in the root area, giving rise to the nodule corresponded to xylem tissue, making the connection between the root and the nodule vasculature. pST6 activity partially resembled that of pST1 as staining was also observed in the vascular cylinder and the parenchymatic tissue surrounding the infected cells (Fig. 5.8, 9, 13, 14). Regarding the root central cylinder, an area of high activity in the vasculature connection between the root and the nodule was observed (Fig. 5.9) and staining in these vascular connections was also evident in the longitudinal sections (Fig. 5.10). The main differences were the wider distribution of $p S T 6$ activity, as it also appeared in the infection zone (Fig. 5.13) and the stronger activity in the meristematic tip (Fig. 5.8, 13).

\section{Fusarium oxysporum infection decreases ST1 and increases ST6 transcript levels and promoter activity}

Fusarium oxysporum f. sp. medicaginis (Fom) is a hemibiotrophic fungus that colonizes roots, compromising plant development. To elucidate whether ST1 and/or ST6 were related to the plant response in such a root pathogenic interaction we analyzed the effect on $S T 1$ and ST6 transcript accumulation and $p S T 1$ and $p S T 6$ promoter activity in $M$. truncatula roots colonized by Fom. Unfortunately, no results were obtained from any transcriptome platform referring to barrel medic-Fo interactions, except for those related to the transcriptome changes in the fungus (Thatcher et al. 2016b).

The infection by Fom in the WT A17 line is shown in Supplementary Fig. S2. During the first 2 dpi, external symptoms of infection could not be detected. Colonization began in the epidermis and progressed through the cortex towards the vascular cylinder. A brown surface discoloration developed on the root starting from $3 \mathrm{dpi}$ that went on to become a massive colonization at $10 \mathrm{dpi}$, at which time necrotic areas could be observed; in fact, in some plants, the roots were macerated (data not shown). The infected plants showed reduced growth, which was clearly visible from 7 dpi, at which time expansion of the first trifoliate leaf is delayed and usually no LR has developed.

ST1 transcript accumulation in Fom infected roots (A17 line) did not show any significant changes with respect to the uninfected (mock) roots (Fig. 6) during the first 3 dpi (Fig. 6a). Later on, ST1 mRNA markedly decreased at 7 and 10 dpi (7.5 and 10 times, respectively) whereas at 15 dpi its level returned to those detected in uninfected roots (Fig. 6a). Unlike ST1, ST6 transcripts clearly increased to up to 6 times in Fom infected roots from the onset of the infection and tended to increase as the infection spread (Fig. 6b). The comparison of STl and ST6 transcript levels showed that $S T 1$ was more abundant, except at 7 and $10 \mathrm{dpi}$ when the amounts were almost equivalent (data not shown).

To study whether Fom infection could trigger major defense signaling pathways, we analyzed the transcript accumulation of some well-known genes of specific routes, $V S P, P R 5$, ethylene response factor $1(E R F 1)$ and hevein like (HEL), as markers of the activation of the JA, SA, ET and JA/ET signaling pathways respectively (Fig. $6 \mathrm{c}-\mathrm{f}$ ). The transcripts of the VSP and ERF1 genes were present in the roots of mock plants, unlike $H E L$ which was not detected, and PR5 transcripts which were barely detected. However, transcripts of all genes were found in Fom-inoculated roots (Fig. 6c-f). Also, the transcripts of VSP increased in Fominoculated plants at the beginning of infection ( $1 \mathrm{dpi})$, but then returned to control levels or even became repressed (at $7 \mathrm{dpi}$ ) as the disease developed (Fig. 6c). PR5 transcription was up-regulated from 2-3 dpi in infected roots and increased markedly until $15 \mathrm{dpi}$, the time at which expression peaked (Fig. 6d). The profile of ERF1 accumulation was similar in both untreated and infected plants until $10 \mathrm{dpi}$. At this time point, ERF1 transcripts had increased sixfold in the plants inoculated with Fom, which was maintained at 15 dpi (Fig. 6e). Finally, HEL transcripts increased progressively from 1 to $3 \mathrm{dpi}$, peaked, and then gradually decreased (Fig. 6f).

The progress of Fom infection in the WT 2HA line (background for the promoter-reporter transgenic barrel medic plants) was similar to that of the WT A17 line, but slightly slower, appearing at $3 \mathrm{dpi}$ and increasing up to $10 \mathrm{dpi}$ when the plants were severely infected (data not shown). The activity of $p S T 1$ and $p S T 6$ was also affected by Fom infection. It was observed that neither the mock nor the infected WT 2HA plants showed GUS activity at any time tested, indicating that Fom endogenous GUS enzymatic activity was inactivated and that the blue color observed in pST::GUS transgenic plants came exclusively from promoter activity (data not shown). As the infection progressed, less pST1 activity was detected in the infected plants as compared to their healthy counterparts (Supplementary Fig. S3). A decrease in the blue staining found in the vascular cylinder was observed near the penetration site of the fungus from 3 dpi onwards. From 10 dpi, the infected plants were severely damaged, and a weak GUS staining was observed where the root was still alive (data not shown). In contrast to $p S T 1$, pST6 activity increased under Fom infection from 3 dpi in both the roots and in the aerial part of the plants (Supplementary Fig. S4). Later on (at stages 10 and 15 dpi), pST6 

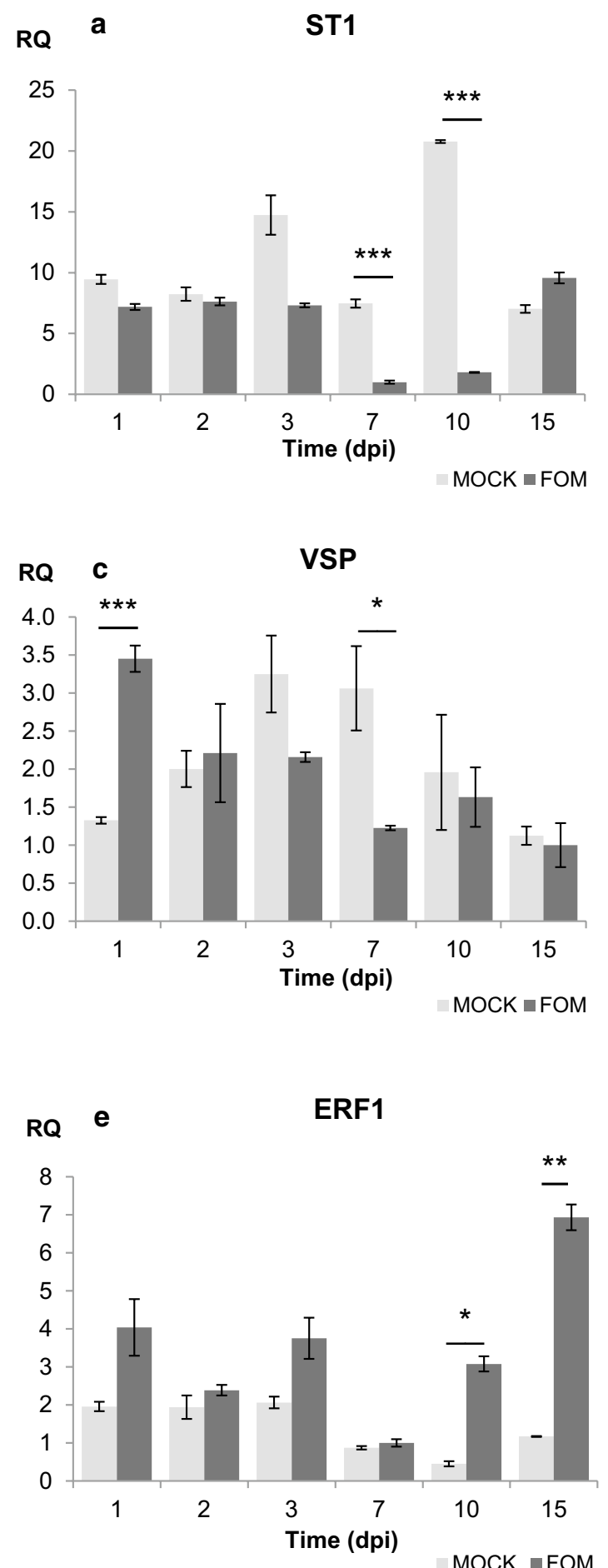

Fig. 6 RT-qPCR of Medicago truncatula ST1 and ST6 transcripts and VSP, ERF1, HEL and PR5 as marker genes for several defense pathways after infection with Fusarium oxysporum f. sp. medicaginis. Transcript accumulation in 1-, 2-, 3-, 7-, 10- and 15-days-post-inoculation (dpi). a $S T 1$. b ST6. c VSP, vegetative storage protein. d PR5, pathogenesis-related 5. e $E R F 1$, ethylene response factor 1 . f $H E L$, hevein-like protein. The expression ratios were normalized by using the Medicago truncatula EFl $\alpha$ gene as an endogenous control. Scale b

ST6
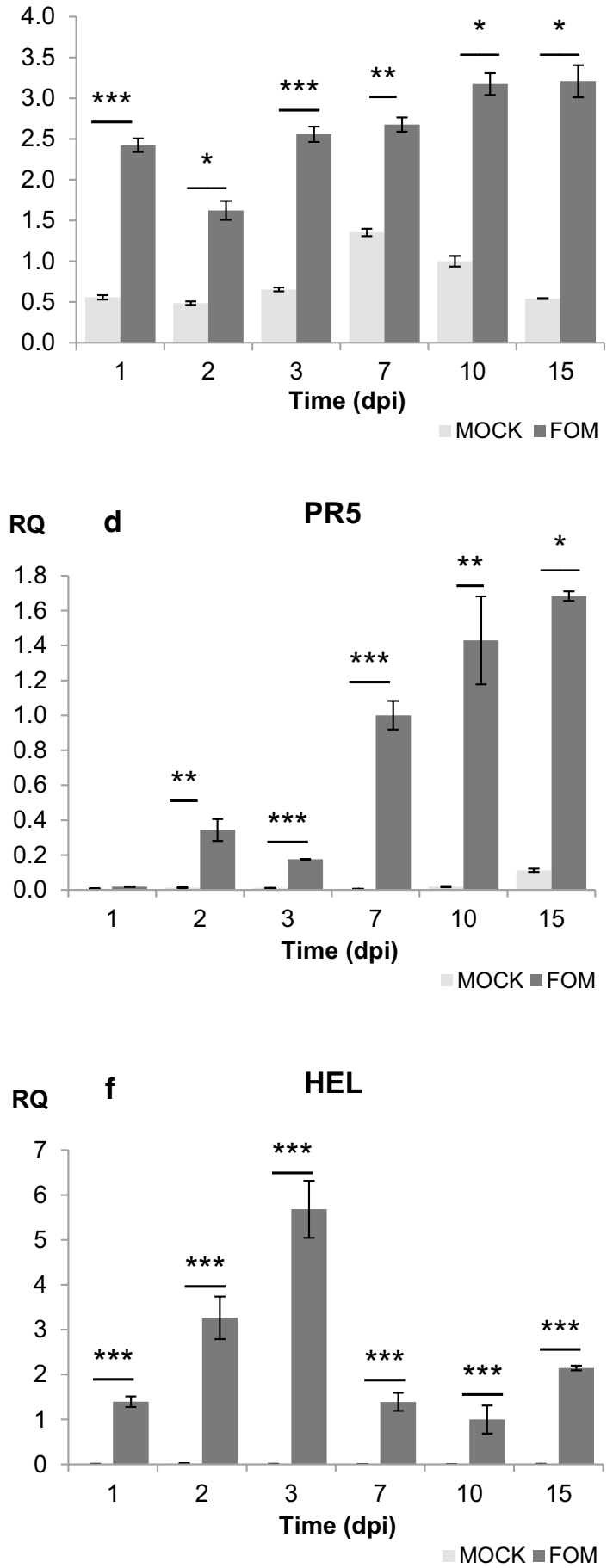

units express normalized relative quantities (RQ). An arbitrary value of 1.0 was denoted for the transcript level of the reference samples being FOM 7 dpi for ST1, PR5 and ERF1, MOCK 10 dpi for ST6, FOM 15 dpi for VSP, and FOM 10 dpi for HEL. Three independent infection experiments were used for RNA extraction. Statistical analyzes were conducted by Student's $t$ test as stated in the "Methods" section considering 3 levels of significance: $* P<0.05$; $* * P<0.01$; $* * * P<0.001$ 
activity remained higher, despite the damage in the PR. In addition, intense staining was observed in the lateral roots (data not shown).

\section{Discussion}

Legumes are important crops in terms of productivity and consumption as they are an excellent nutrient source. While they establish important symbiosis related to $\mathrm{N}_{2}$ fixation, which increases soil quality, they can also be attacked by pathogens which can lead to reduced productivity. The establishment of beneficial and pathogenic interactions in legumes makes them a good model to perform comparative studies, as it is known that several genes are involved in the recognition and response to these interactions (Rey and Jacquet 2018). While most cultivated legumes are not good model systems, Medicago truncatula, with a relatively small diploid genome, is an appropriate species for performing genomic research (Benedito et al. 2008).

Two M. truncatula proteins, ST1 and ST6, belonging to the ST family (Albornos et al. 2012), are considered to be associated with plant nutritional status and $\mathrm{N}_{2}$-fixing symbiosis (ST1) and biotrophic interactions mediated by SA (ST6) based on their responses to hormonal treatments (Albornos et al. 2017, 2018). The high levels of ST1 and ST6 transcripts and promoter activities in roots, together with a high number of root-associated cis-acting regulatory elements in their promoters (Albornos et al. 2017, 2018), and the existence of two ST1 specific microRNA that decreases in root-forming callus (Eyles et al. 2013) indicate that ST1 and ST6 are probably, although not exclusively (Albornos et al. 2019), involved in root biology. In this study, we deepen our understanding of the role of ST1 and ST6 proteins in the physiological processes that take place in the root system, including PR development, LR formation, nodule establishment, and fungal infection.

The higher activity of $p S T 1$ and $p S T 6$ in younger roots (Figs. 1a, 2a) and most apical root areas (Figs. 1b1-3, 2b1-3, S1, Table 1) confirm previously published microarray data (Benedito et al. 2008; Hruz et al. 2008) and indicate a relationship between ST1 and ST6 and root biology and a possible role in PR and LR development. Our results highlight that the function of these two genes could involve the vascular cylinder, as has been previously reported in reproductive organs (Albornos et al. 2019).

Both promoters are active in the pericycle and the first dividing cells giving rise to LR primordia (LRP) (Figs. 1b9, 2b8), indicating a putative role in LRP formation as $p S T 1$ and pST6 are not active in endodermal and cortical cells in areas where no LR are forming (Figs. 1b2, 2b2). However, while $p S T 1$ becomes inactive early on (Fig. 1b8, b9) throughout the establishment of the meristems of lateral roots and LR emergence, pST6 remains active (Fig. 2a3, b7-b9).

The differences observed in the root meristematic area, where only pST6 is active, are in accordance with the regulation exerted by IAA and cytokinin (CK), the hormones that basically control PR and LR organogenesis, in STl and ST6 transcript accumulation. STI is induced by IAA and CK (Albornos et al. 2017) and reduced by IAA polar transport inhibitors (Hruz et al. 2008), while ST6 is up-regulated by IAA and down-regulated by CK (Albornos et al. 2018), which is in line with the need for high levels of IAA and low levels of CK for root apical meristem initiation and maintenance (Oldroyd et al. 2011). The role of ST6 in meristematic tissues is supported by many results which include the high activity of its promoter in PR, LR, and nodule meristems (Figs. 2, 5, S2) and in vascular cambium and pericycle (Fig. 2b4, b5), as well as high levels of transcript accumulation in callus and cell suspension cultures, as retrieved from microarray databases (Hruz et al. 2008). The lack of $p S T 1$ activity in apical meristems and its prevalence in vascular tissues, lead us to reinforce the previously hypothesized nutritional role of ST1, although the specific function in this process remains elusive.

The nodule developmental program is derived from the LR program and there is a potential interconnection between both processes (Franssen et al. 2015). Owing to the possible involvement of ST1 and ST6 proteins in LR development (Figs. 1, 2), their previously postulated participation in biotic interactions (Albornos et al. 2017, 2018), the ST1 association with plant nutrient status (Albornos et al. 2017), the detection of two cis-acting regulatory elements related to nodule expression in their promoters (Albornos et al. 2017, 2018) and their presence in nodules, as indicated in most transcriptomic databases (Benedito et al. 2008; Hruz et al. 2008; Roux et al. 2014; Li et al. 2016; Carrère et al. 2020), we analyzed how the inoculation of $M$. truncatula plants with the rhizobacteria S. meliloti (Sm) affects ST1 and ST6. The results obtained in this research point to the involvement of ST1 and ST6 in this biological interaction. Their putative participation in two main processes required to reach a proper $\mathrm{N}_{2}$ fixation: nodule organogenesis and bacterial infection, will be discussed.

The ST1 and ST6 levels are always higher in the inoculated root (root areas with no nodules, $\mathrm{nr}$ in the figure) than in the nodules (Fig. 3a, b) which clearly contrast with mRNA accumulation of the two nodulation markers tested (Fig. 3c, d). These results indicate that probably ST1 and ST6 do not have a role in the symbiosis establishment but in the nodule development, which might be homologous to their role in the LR formation. However, comparing the opposite accumulation pattern of $S T 1$ (Fig. 3a) and ST6 (Fig. 3b) transcripts in the inoculated roots with respect to control roots, we can postulate that ST1 and ST6 play different roles in 
these roots. As ST1 protein might have a role in nutrition (Albornos et al. 2017), the increase of STl transcripts in infected roots (Fig. 3a) could be related to the changes in the nutrient mobilization as a consequence of the symbiotic interaction, even before the nodule actually starts to fix $\mathrm{N}_{2}$.

JA and SA are the main hormones that increase the accumulation of $S T 1$ and ST6 transcripts, respectively (Albornos et al. 2017, 2018), therefore we checked the VSP and PR5 marker genes (Fig. 3e, f), as an indicator of the hormonal changes in the interaction. VSP expression throughout the nodulation assay indicates no specific activation of JA signaling (Fig. 3e) which is in accordance with previous reports stating that JA does not affect nodulation (Zdyb et al. 2011). Hence, this hormone, which increases STI transcripts in seedlings (Albornos et al. 2017), is probably not a major regulator of $S T 1$ upregulation in roots in the rhizobial symbiosis (Fig. 3a). We observed a decrease in the SA marker gene PR5 in the nodulated roots (Fig. 3f), and similar findings were reported by other authors (Chen et al. 2017). Therefore, a general reduction in SA upregulated transcripts in the inoculated roots could explain the decrease of ST6 (Fig. 3b), as observed for several defense genes in the interaction M. truncatula-Sm (Maunoury et al. 2010). This is probably because the root immune system must be adapted to avoid defense (Gourion et al. 2015) and partial suppression of the SA signaling is needed to allow symbiotic associations (Alonso-Ramírez et al. 2014). The reduction of $P R 5$ in nodulated roots, contrasts with the high levels of this transcript found inside the nodule (Fig. 5f) and points to an active SA response in this organ.

Finally, our results confirm that $S T 1$ and $S T 6$ transcripts accumulate in nodules (Fig. 3a, b), although to a lesser extent than the nodulation marker genes assayed (Fig. 3c, d) and point to a putative role of ST1 and ST6 in this organ. Several data also support this role, such as the activity of $p S T 1$ (Fig. 4) and pST6 (Fig. 5) in some specific tissues within the nodule from the onset of the interaction (Figs. 4.1-4, 5.1-5), the increase of ST6 transcript found by microarray analysis after the inoculation of M. truncatula with exoA Sm mutant (Moreau et al. 2011; Carrère et al. 2020), the changes of ST1 transcript levels in the $b z r$ and $d m i 3$ barrel medic mutants (Camps et al. 2015; Carrère et al. 2020) and the effect of IAA and cytokinin in $S T 1$ and ST6 transcript accumulation (Albornos et al. 2017, 2018).

The analysis of our results allows us to speculate that ST1 and ST6 participate in different aspects of nodule development. Firstly, we can propose that ST1 and ST6 are involved in nodule primordia initiation as their promoters showed high activity at this developmental stage (Figs. 4.1, 5.1) showing specific activation in the root cortical cells at the beginning of the infection (Figs. 4.3, 4, 5.3, 4). Also, their transcripts are both upregulated by IAA (Albornos et al. 2017, 2018), being local high IAA required to start this developmental program (van Noorden et al. 2006). In later stages of nodulation, high pST1 activity in the vascular tissue (Fig. 4.7, 10) and high pST6 activity in the nodule meristem (Fig. 5.9, 13) may indicate that both proteins are specifically involved in their development. The higher activity of $p S T 1$ around vascular bundles (Fig. 4.9,14) could be associated with its function in nutrient transport, uptake and/ or delivery. These patterns resemble the ones observed in root initiation and development (Figs. 1a1, b9, 2a1, b3) and suggest that the function of ST1 and ST6 is equivalent in both organs, although determining its specific role requires further investigation.

M. truncatula interaction with $\mathrm{Sm}$ leads to cylindricalshaped indeterminate nodules with several histological zones with different functions (Vasse et al. 1990). Hence, additional roles of ST1 and ST6 proteins should not be discarded, according to the activity of their promoters (Figs. 4, 5). pSTI and $p S T 6$ are active in the uninfected cells (Figs. 4.7, 5.8), within the fixation region of the nodule, which are related to nutrient exchange between the plant and the bacteria and also to the defense response against pathogens (Limpens et al. 2013). These roles have been previously associated with ST1 (Albornos et al. 2017) and ST6 (Albornos et al. 2018), respectively.

Furthermore, $p S T 6$ is active in the nodule infection zone (Fig. 5.13) where the perception of nod factors is thought to be active (Limpens et al. 2013). pST6 induction in this zone could be controlled by the activation of the SYM pathway, as there is evidence that ST6 expression is regulated by this signaling route (Kuhn et al. 2010). Also, it would explain the pST6 activity found in the cortical cells upon infection (Fig. 5.3) and the transcript accumulation in the nodule (Fig. 3b), indicating that ST6 has a role in the early nodule development.

In sum, we hypothesize that ST1 and ST6 proteins are mainly needed for proper nodule formation and maintenance. Also, we speculate that ST1 could have a nutritional function in the nodule cells and maybe a similar role in the root and nodule vasculature. Differently, ST6 could have a basal defensive role inside the nodule via a SA-mediated response.

In addition to the involvement of ST1 and ST6 in root development and nodulation, we assessed their possible participation in interactions with root pathogens, since some genes are related to the recognition and response to beneficial and pathogenic microbes. To this end, we infected M. truncatula (lines A17 and 2HA) with Fusarium oxysporum f. sp. medicaginis strain 179.29 (Fom), a root-infecting pathogenic fungus that clogs vascular tissue at late stages of infection.

In the plant defense response against pathogens, usually SA signaling triggers resistance against biotrophic and hemibiotrophic pathogenic fungi (Pieterse et al. 2012), and 
a combination of JA and ET signaling pathways activates resistance against necrotrophs (Glazebrook 2005). Nevertheless, in the case of the hemibiotrophic fungus $F$. oxysporum ( $F o$ ), the involvement of the SA, ET and JA signaling pathways depends on the specific forma specialis-host interaction (Di et al. 2016; Thatcher et al. 2016a). Since the hormonal pathways involved in the interaction between $M$. truncatula and Fom have not been widely investigated, and no data has been found in the transcriptomic databases (Carrère et al. 2020), this work contributes to understanding the defense network activated during this infection and how it is related to the regulation of $S T 1$ and ST6 by JA, SA and ET (Albornos et al. 2017, 2018).

Throughout the infection process, ST6 gene expression (Fig. 6b) and pST6 activity (Supplementary Fig. S4) increase, while $S T 1$ transcripts (Fig. 6a) and $p S T 1$ activity (Supplementary Fig. S3) decrease, suggesting that ST6 but not ST1 has a role in the recognition of Fom and its colonization process.

ST6 is the only transcript within the M. truncatula ST family whose expression is induced by SA and ET (Albornos et al. 2018), whose combined action has been reported in some hemibiotrophic interactions (Šašek et al. 2012). In our pathosystem M. truncatula-Fom, the up-regulation of PR5 gene (marker of SA-signaling) in infected roots (Fig. 6d), suggests the activation of the SA-mediated response against the pathogen as it was previously described for other plantFo interactions (Berrocal-Lobo and Molina 2008; NiñoSánchez et al. 2015; Di et al. 2017). The activation of the SA-mediated response in our system was observed from 2 dpi onwards (Fig. 6d), similar to that described in the infection of common bean plants by $F$. oxysporum f. sp. phaseoli (Niño-Sánchez et al. 2015). This indicates that in both pathosystems, SA is not related to the pathogen recognition but to the infection response initiated afterward and could be responsible for the increase in ST6 observed.

The transcript accumulation patterns of PR5 (Fig. 6d) and ST6 (Fig. 6b) do not coincide exactly, suggesting the collaboration of other hormones in ST6 regulation in this plant-fungus interaction, presumably ET, as it has been demonstrated in other plant-Fo interactions (Šašek et al. 2012). At the end of the infection by Fom, once the fungus has colonized the vascular bundles and the severely damaged roots start to die (Supplementary Fig. S2), the ET-signaling pathway, through its marker gene ERF1, is induced (Fig. 6e). The overexpression of MtERF1 does not confer increased resistance to Fo (Anderson and Singh 2011); therefore, the late up-regulation of ERF1 observed under our conditions would take place when the tissue is macerated in a necrotrophic-like interaction, typically orchestrated by ET (Glazebrook 2005). The up-regulation of ET marker genes was also observed in plant-Fo interactions with tomato (Di et al. 2017) and common bean (Niño-Sánchez et al. 2015), but not with other species (Berrocal-Lobo and Molina 2008; Thatcher et al. 2016a) and depending on the role of ET in each plant species.

The transcript accumulation profile of HEL (Fig. 6f), the marker gene of the JA/ET pathway in Arabidopsis (Pré et al. 2008) and barrel medic (Paudel and Bede 2015), in $M$. truncatula roots during Fom infection suggests that the JA/ET signaling pathway could be mainly involved in the recognition and first stages of colonization in the interaction. In fact, the up-regulation of the JA-signaling marker gene, VSP, in infected roots at $1 \mathrm{dpi}$ (Fig. 6c) also suggests that the JA-signaling pathway via VSP is related to pathogen recognition. However, the relationship between JA/ET signaling and ST6 in the defense response against Fom should be considered with care and could differ depending on pathogen lifestyle (Samac et al. 2011). In fact, the JA/ET pathway is activated in necrotrophic interactions and mechanical damage (Benedito et al. 2008; Pieterse et al. 2012) but no changes in ST6 transcript levels are detected (Hruz et al. 2008; Albornos et al. 2018)Albornos et al. 2018).

The results presented here indicate the presence of a coordinated network of hormone-mediated pathways in the Fom-barrel medic interaction, where JA-signaling is the first to be activated, presumably for the recognition of the fungal pathogen, followed by the activation of SA-pathway, which remains activated until the end of the process. The ET-signaling pathway on the other hand is active in the late stages of the infection when the interaction resembles a necrotrophiclike infection. Despite the activation of all hormonally regulated defensive pathways (Fig. 6c-f), the plant is colonized by Fom and eventually dies (Supplementary Fig. S2), confirming the susceptibility of lines A17 and 2HA, as has been previously described (Ramírez-Suero et al. 2010).

Throughout Fom infection, ST6 transcript accumulation (Fig. 6b) and pST6 activity (Supplementary Fig. S4) are similar to those found in interactions with arbuscular mycorrhizal fungi interactions (Liu et al. 2007). This leads us to speculate that ST6 has a dual function in symbiotic and pathogenic interactions with fungi, as reported for other proteins (Wang et al. 2012; Oldroyd 2013), forming part of the signaling that involves SA and/or ET. This dual function has not been described for other ST proteins up-regulated by Fusarium in other species (Marquez et al. 2019), confirming the specific functions proposed for this multigenic family (Albornos et al. 2012, 2017, 2018).

In sum, we can state that proteins ST1 and ST6 perform different roles in primary and lateral root development as both participate in vasculature development, whereas only ST6 is related to meristem activity. Furthermore, ST1 and ST6 have different roles in biotic interactions since their encoding genes are regulated differently; $S T 1$ is induced in plants challenged with an $\mathrm{N}_{2}$-fixing bacterium such as $S m$ and ST6 is induced during the interaction with a 
hemibiotrophic pathogen like Fom. The role of these proteins in symbiosis might be related to nodule organogenesis rather than to the establishment of bacterial interactions. Additionally, ST6, but not ST1, is involved in the recognition and infection progress in the Fom pathogenic interaction with $M$. truncatula. Finally, inoculation of barrel medic with Fom induces the activation of a coordinated network of hormone-mediated pathways that includes JA, SA and ET.

Author contribution statement LA carried out the construction of transgenic plants and the GUS assays, performed the $S m$ inoculation and the related RT-qPCR experiments and data analyzes, participated in the study design, and in the writing of the manuscript. VC-dC carried out the Fom infection and related RT-qPCR experiments and data analysis and helped to write the manuscript. IM prepared the histological sections and participated in the study design. JMD-M, design the Fom experiment and helped to write the manuscript. EL conceptualized the study, participated in its design, and helped to write the manuscript. BD also conceptualized the study, participated in its design and coordination, assisted in the construction of transgenic plants and GUS assays, and helped to write the manuscript. All authors have read and approved the final manuscript.

Acknowledgements We thank Dr. Barker and Dr. Chabaud (INRACNRS, Toulouse, France) for their help in training L. Albornos to carry out the Medicago truncatula transformation protocol. We also thank Martina Rickauer (Université de Toulouse, France) for kindly providing strain 179.29 (Fusarium oxysporum f. p. medicaginis).

Funding This research was supported by grants BFU2013-44793-P and AGL2015-66131-C2-1-R from Ministerio de Economía y Competitividad (MINECO, Spain). L. Albornos (AP2009-2637) and V. Casado-del-Castillo (AP2010-2742) were recipient of fellowship from Ministerio de Educación, Cultura y Deporte (MECD, Spain).

\section{Compliance with ethical standards}

Conflict of interest The authors declare that they have no known competing financial interests or personal relationships that could have appeared to influence the work reported in this paper.

\section{References}

Albornos L, Martín I, Hernández-Nistal J, Labrador E, Dopico B (2018) Three members of Medicago truncatula ST family (MtST4, MtST5 and MtST6) are specifically induced by hormones involved in biotic interactions. Plant Physiol Biochem 127:496505. https://doi.org/10.1016/j.plaphy.2018.04.019

Albornos L, Martín I, Iglesias R, Jiménez T, Labrador E, Dopico B (2012) ST proteins, a new family of plant tandem repeat proteins with a DUF2775 domain mainly found in Fabaceae and Asteraceae. BMC Plant Biol 12:207. https://doi. org/10.1186/1471-2229-12-207
Albornos L, Martín I, Labrador E, Dopico B (2017) Three members of Medicago truncatula ST family are ubiquitous during development and modulated by nutritional status (MtST1) and dehydration (MtST2 and MtST3). BMC Plant Biol 17:117. https ://doi.org/10.1186/s12870-017-1061-z

Albornos L, Martín I, Labrador E, Dopico B (2019) Promoter activity of the genes encoding the specific tissue protein family in the reproductive organs of Medicago truncatula. Biol Plant 63:785-796. https://doi.org/10.32615/bp.2019.111

Alonso-Ramírez A, Poveda J, Martín I, Hermosa R, Monte E, Nicolás C (2014) Salicylic acid prevents Trichoderma harzianum from entering the vascular system of roots. Mol Plant Pathol 15:823-831. https://doi.org/10.1111/mpp.12141

Alves-Santos FM, Benito EP, Eslava AP, Díaz-Mínguez J (1999) Genetic diversity of Fusarium oxysporum strains from common bean fields in Spain. Appl Environ Microbiol 65:3335-3340

Anderson JP, Singh KB (2011) Interactions of Arabidopsis and $M$. truncatula with the same pathogens differ in dependence on ethylene and ethylene response factors. Plant Signal Behav 6:551-552. https://doi.org/10.4161/psb.6.4.14897

Ardourel M, Demont N, Debellé F, Maillet F, de Billy F, Promé JC, Dénarié J, Truchet G (1994) Rhizobium meliloti lipooligosaccharide nodulation factors: different structural requirements for bacterial entry into target root hair cells and induction of plant symbiotic developmental responses. Plant Cell 6:1357-1374. https://doi.org/10.1105/tpc.6.10.1357

Barker DG, Faff T, Moreau D, Groves E, Ruffel S, Lepetit M, Whitehand S, Maillet F, Nair RM, Journet E (2006) Growing M. truncatula: choice of substrates and growth conditions. In: The Medicago truncatula handbook. The Samuel Roberts Noble Foundation, Ardmore, pp 1-26. http://www.noble.org/Medic agoHandbook

Benedito VA, Torres-Jerez I, Murray JD, Andriankaja A, Allen S, Kakar K, Wandrey M, Verdier J, Zuber H, Ott T, Moreau S, Niebel A, Frickey T, Weiller G, He J, Dai X, Zhao PX, Tang Y, Udvardi MK (2008) A gene expression atlas of the model legume Medicago truncatula. Plant J 55:504-513. https://doi.org/10.1111/ j.1365-313X.2008.03519.x

Berrocal-Lobo M, Molina A (2008) Arabidopsis defense response against Fusarium oxysporum. Trends Plant Sci 13:145-150. https ://doi.org/10.1016/J.TPLANTS.2007.12.004

Camps C, Jardinaud M-F, Rengel D, Carrère S, Hervé C, Debellé F, Gamas P, Bensmihen S, Gough C (2015) Combined genetic and transcriptomic analysis reveals three major signalling pathways activated by Myc-LCOs in Medicago truncatula. New Phytol 208:224-240. https://doi.org/10.1111/nph.13427

Cao Y, Halane MK, Gassmann W, Stacey G (2017) The role of plant innate immunity in the legume-rhizobium symbiosis. Annu Rev Plant Biol 68:535-561. https://doi.org/10.1146/annurev-arpla nt-042916-041030

Carrère S, Verdenaud M, Gough C, Gouzy J, Gamas P (2020) LeGOO: an expertized knowledge database for the model legume Medicago truncatula. Plant Cell Physiol 61:203-211. https://doi. org/10.1093/pcp/pcz177

Chabaud M, de Carvalho-Niebel F, Barker DG (2003) Efficient transformation of Medicago truncatula $\mathrm{cv}$. Jemalong using the hypervirulent Agrobacterium tumefaciens strain AGL1. Plant Cell Rep 22:46-51. https://doi.org/10.1007/s00299-003-0649-y

Chen T, Duan L, Zhou B, Yu H, Zhu H, Cao Y, Zhang Z (2017) Interplay of pathogen-induced defense responses and symbiotic establishment in Medicago truncatula. Front Microbiol 8:973. https:// doi.org/10.3389/fmicb.2017.00973

de Vega-Bartol JJ, Martín-Dominguez R, Ramos B, García-Sánchez M-A, Díaz-Mínguez JM (2011) New virulence groups in Fusarium oxysporum f. sp. phaseoli : the expression of the gene coding for the transcription factor $\mathrm{ftf} 1$ correlates with virulence. 
Phytopathology 101:470-479. https://doi.org/10.1094/PHYTO -09-10-0252

Di X, Gomila J, Takken FLW (2017) Involvement of salicylic acid, ethylene and jasmonic acid signalling pathways in the susceptibility of tomato to Fusarium oxysporum. Mol Plant Pathol 18:1024 1035. https://doi.org/10.1111/mpp.12559

Di X, Takken FLW, Tintor N (2016) How phytohormones shape interactions between plants and the soil-borne fungus Fusarium oxysporum. Front Plant Sci 7:170. https://doi.org/10.3389/ fpls.2016.00170

Eyles RP, Williams PH, Ohms SJ, Weiller GF, Ogilvie HA, Djordjevic MA, Imin N (2013) microRNA profiling of root tissues and root forming explant cultures in Medicago truncatula. Planta 238:91105. https://doi.org/10.1007/s00425-013-1871-7

Franssen HJ, Xiao TT, Kulikova O, Wan X, Bisseling T, Scheres B, Heidstra R (2015) Root developmental programs shape the Medicago truncatula nodule meristem. Development 142:2941-2950. https://doi.org/10.1242/dev.120774

Gao L-L, Anderson JP, Klingler JP, Nair RM, Edwards OR, Singh KB (2007) Involvement of the octadecanoid pathway in bluegreen aphid resistance in Medicago truncatula. Mol Plant Microbe Interact 20:82-93. https://doi.org/10.1094/MPMI-20-0082

Glazebrook J (2005) Contrasting mechanisms of defense against biotrophic and necrotrophic pathogens. Annu Rev Phytopathol 43:205-227. https://doi.org/10.1146/annurev.phyto.43.04020 4.135923

Gourion B, Berrabah F, Ratet P, Stacey G (2015) Rhizobium-legume symbioses: the crucial role of plant immunity. Trends Plant Sci 20:186-194. https://doi.org/10.1016/j.tplants.2014.11.008

Horváth B, Domonkos Á, Kereszt A, Szúcs A, Ábrahám E, Ayaydin F, Bóka K, Chen Y, Chen R, Murray JD, Udvardi MK, Kondorosi É, Kaló P (2015) Loss of the nodule-specific cysteine rich peptide, NCR169, abolishes symbiotic nitrogen fixation in the Medicago truncatula dnf7 mutant. Proc Natl Acad Sci USA 112:1523215237. https://doi.org/10.1073/pnas.1500777112

Hruz T, Laule O, Szabo G, Wessendorp F, Bleuler S, Oertle L, Widmayer P, Gruissem W, Zimmermann P (2008) Genevestigator V3: a reference expression database for the meta-analysis of transcriptomes. Adv Bioinform 2008:1-5. https://doi. org/10.1155/2008/420747

Kuhn H, Küster H, Requena N (2010) Membrane steroid-binding protein 1 induced by a diffusible fungal signal is critical for mycorrhization in Medicago truncatula. New Phytol 185:716-733. https ://doi.org/10.1111/j.1469-8137.2009.03116.x

Li J, Dai X, Zhuang Z, Zhao PX (2016) LegumeIP 2.0—a platform for the study of gene function and genome evolution in legumes. Nucleic Acids Res 44:1189-1194. https://doi.org/10.1093/nar/ gkv1237

Limpens E, Moling S, Hooiveld G, Pereira PA, Bisseling T, Becker JD, Küster H (2013) Cell- and tissue-specific transcriptome analyses of Medicago truncatula root nodules. PLoS ONE 8:e64377. https ://doi.org/10.1371/journal.pone.0064377

Liu J, Maldonado-Mendoza I, Lopez-Meyer M, Cheung F, Town CD, Harrison MJ (2007) Arbuscular mycorrhizal symbiosis is accompanied by local and systemic alterations in gene expression and an increase in disease resistance in the shoots. Plant J 50:529-544. https://doi.org/10.1111/j.1365-313X.2007.03069.x

Livak KJ, Schmittgen TD (2001) Analysis of relative gene expression data using real-time quantitative PCR and the $2^{-\Delta \Delta C T}$ method. Methods 25:402-408. https://doi.org/10.1006/METH.2001.1262

Maunoury N, Redondo-Nieto M, Bourcy M, Van de Velde W, Alunni B, Laporte P, Durand P, Agier N, Marisa L, Vaubert D, Delacroix H, Duc G, Ratet P, Aggerbeck L, Kondorosi E, Mergae (2010) Differentiation of symbiotic cells and endosymbionts in Medicago truncatula nodulation are coupled to two transcriptome-switches.
PLoS ONE 5:e9519. https://doi.org/10.1371/journal.pone.00095 19

Marquez N, Giachero ML, Gallou A, Debat HJ, Declerck S, Ducasse DA (2019) Transcriptome analysis of mycorrhizal and nonmycorrhizal soybean plantlets upon infection with Fusarium virguliforme, one causal agent of sudden death syndrome. Plant Pathol 68:470-480. https://doi.org/10.1111/ppa.12964

Mohd-Radzman NA, Djordjevic MA, Imin N (2013) Nitrogen modulation of legume root architecture signaling pathways involves phytohormones and small regulatory molecules. Front Plant Sci 4:385. https://doi.org/10.3389/fpls.2013.00385

Moreau S, Verdenaud M, Ott T, Letort S, de Billy F, Niebel A, Gouzy J, de Carvalho-Niebel F, Gamas P (2011) Transcription reprogramming during root nodule development in Medicago truncatula. PLoS ONE 6:e16463. https://doi.org/10.1371/journal.pone.00164 63

Niño-Sánchez J, Tello V, del Castillo VC, Thon MR, Benito EP, DíazMínguez JM (2015) Gene expression patterns and dynamics of the colonization of common bean (Phaseolus vulgaris L.) by highly virulent and weakly virulent strains of Fusarium oxysporum. Front Microbiol 6:1-14. https://doi.org/10.3389/fmicb.2015.00234

Oldroyd GED (2013) Speak, friend, and enter: signalling systems that promote beneficial symbiotic associations in plants. Nat Rev Microbiol 11:252. https://doi.org/10.1038/nrmicro2990

Oldroyd GED, Murray JD, Poole PS, Downie JA (2011) The rules of engagement in the legume-rhizobial symbiosis. Annu Rev Genet 45:119-144. https://doi.org/10.1146/annurev-genet-110410-13254 9

Paudel JR, Bede JC (2015) Ethylene signaling modulates herbivoreinduced defense responses in the model legume Medicago truncatula. Mol Plant Microbe Interact 28:569-579. https://doi. org/10.1094/MPMI-10-14-0348-R

Pichon M, Journet E-P, de Billy F, Dedieu A, Huguet T, Truchet G, Barker DG (1994) ENOD12 gene expression as a molecular marker for comparing Rhizobium-dependent and -independent nodulation in alfalfa. Mol Plant Microbe Interact 7:740-747

Pieterse CMJ, Van der Does D, Zamioudis C, Leon-Reyes A, Van Wees SCM (2012) Hormonal modulation of plant immunity. Annu Rev Cell Dev Biol 28:489-521. https://doi.org/10.1146/annurev-cellb io-092910-154055

Pré M, Atallah M, Champion A, De Vos M, Pieterse CMJ, Memelink $\mathrm{J}$ (2008) The AP2/ERF domain transcription factor ORA59 integrates jasmonic acid and ethylene signals in plant defense. Plant Physiol 147:1347-1357. https://doi.org/10.1104/pp.108.117523

Ramírez-Suero M, Khanshour A, Martinez Y, Rickauer M (2010) A study on the susceptibility of the model legume plant Medicago truncatula to the soil-borne pathogen Fusarium oxysporum. Eur J Plant Pathol 126:517-530. https://doi.org/10.1007/s1065 8-009-9560-x

Rey T, Jacquet C (2018) Symbiosis genes for immunity and vice versa. Curr Opin Plant Biol 44:64-71. https://doi.org/10.1016/j. pbi.2018.02.010

Roux B, Rodde N, Jardinaud MF, Timmers T, Sauviac L, Cottret L, Carrère S, Sallet E, Courcelle E, Moreau S, Debellé F, Capela D, De Carvalho-Niebel F, Gouzy J, Bruand C, Gamas P (2014) An integrated analysis of plant and bacterial gene expression in symbiotic root nodules using laser-capture microdissection coupled to RNA sequencing. Plant J 77:817-837. https://doi.org/10.1111/ tpj. 12442

Samac DA, Peñuela S, Schnurr JA, Hunt EN, Foster-Hartnett D, VanDenBosch KA, Gantt JS (2011) Expression of coordinately regulated defence response genes and analysis of their role in disease resistance in Medicago truncatula. Mol Plant Pathol 12:786-798. https://doi.org/10.1111/j.1364-3703.2011.00712.x 
Šašek V, Nováková M, Jindřichová B, Bóka K, Valentová O, Burketová L (2012) Recognition of avirulence gene AvrLm1 from hemibiotrophic ascomycete Leptosphaeria maculans triggers salicylic acid and ethylene signaling in Brassica napus. Mol Plant Microbe Interact 25:1238-1250. https://doi.org/10.1094/ MPMI-02-12-0033-R

Thatcher LF, Gao L-L, Singh K (2016a) Jasmonate signalling and defence responses in the model legume Medicago truncatula -a focus on responses to Fusarium wilt disease. Plants 5:11. https:// doi.org/10.3390/plants5010011

Thatcher LF, Williams AH, Garg G, Buck SAG, Singh KB (2016b) Transcriptome analysis of the fungal pathogen Fusarium oxysporum $\mathrm{f}$. sp. medicaginis during colonisation of resistant and susceptible Medicago truncatula hosts identifies differential pathogenicity profiles and novel candidate effectors. BMC Genom 17:860. https://doi.org/10.1186/s12864-016-3192-2

Van Noorden GE, Ross JJ, Reid JB, Rolfe BG, Mathesiu U (2006) Defective long-distance auxin transport regulation in the Medicago truncatula supernumeric nodules mutant. Plant Physiol 140:1494-1506. https://doi.org/10.1104/pp.105.075879
Vasse J, de Billy F, Camut S, Truchet G (1990) Correlation between ultrastructural differentiation of bacteroids and nitrogen fixation in alfalfa nodules. J Bacteriol 172:4295-4306. https://doi. org/10.1128/jb.172.8.4295-4306.1990

Wang E, Schornack S, Marsh JF, Gobbato E, Schwessinger B, Eastmond P, Schultze M, Kamoun S, Oldroyd GED (2012) A common signaling process that promotes mycorrhizal and oomycete colonization of plants. Curr Biol 22:2242-2246. https://doi. org/10.1016/J.CUB.2012.09.043

Zdyb A, Demchenko K, Heumann J, Mrosk C, Grzeganek P, Göbel C, Feussner I, Pawlowski K, Hause B (2011) Jasmonate biosynthesis in legume and actinorhizal nodules. New Phytol 189:568-579. https://doi.org/10.1111/j.1469-8137.2010.03504.x

Publisher's Note Springer Nature remains neutral with regard to jurisdictional claims in published maps and institutional affiliations.

\section{Affiliations}

\section{Lucía Albornos $^{1,3} \cdot$ Virginia Casado-del-Castillo ${ }^{2,3} \cdot$ Ignacio Martín $^{1,3}$ • José M. Díaz-Mínguez ${ }^{2,3} \cdot$ Emilia Labrador $^{1,3}$. Berta Dopico ${ }^{1,3}$ (D)}

\author{
Lucía Albornos \\ lucialbornos@usal.es \\ Virginia Casado-del-Castillo \\ virginiacasado@usal.es \\ Ignacio Martín \\ a56562@usal.es
}

José M. Díaz-Mínguez

josediaz@usal.es

Emilia Labrador

labrador@usal.es
1 Departamento de Botánica y Fisiología Vegetal, Universidad de Salamanca, C/ Licenciado Méndez Nieto s/n, Campus Miguel de Unamuno, 37007 Salamanca, Spain

2 Departamento de Microbiología y Genética, Universidad de Salamanca, Campus Miguel de Unamuno, Edificio departamental, 37007 Salamanca, Spain

3 Instituto Hispano-Luso de Investigaciones Agrarias (CIALE), Universidad de Salamanca, Campus de Villamayor, C/ Río Duero 12, Villamayor, 37185 Salamanca, Spain 